\title{
Clinical features and prognostic factors of combined small cell lung cancer: development and validation of a nomogram based on the SEER database
}

\author{
Lan Yang ${ }^{1 \#} \wedge$, Yuwen Zhou ${ }^{2 \#}$, Gang Wang ${ }^{3} \wedge$, Dan Liu ${ }^{1} \wedge$, Bojiang Chen ${ }^{1}$, Dan Pu ${ }^{1} \wedge$, Pierpaolo Correale ${ }^{4}$, \\ Dirk Rades ${ }^{5}$, Yusuke Tomita ${ }^{6}$, Alessandro Inno ${ }^{7}$, Mariacarmela Santarpia ${ }^{8}$, Yalun $\mathrm{Li}^{9 *}$, Weimin $\mathrm{Li}^{1{ }^{1,10} \wedge}$ \\ ${ }^{1}$ Department of Respiratory and Critical Care Medicine, West China Hospital, Sichuan University, Chengdu, China; ${ }^{2}$ Department of Biotherapy, \\ Cancer Center, West China Hospital, Sichuan University, Chengdu, China; ${ }^{3}$ Department of Respiratory and Critical Care Medicine, Clinical \\ Research Centre for Respiratory Disease, West China Hospital, Sichuan University, Chengdu, China; ${ }^{4}$ Medical Oncology Unit, Grand Metropolitan \\ Hospital "Bianchi-Melacrino-Morelli”, Reggio Calabria, Italy; ${ }^{5}$ Department of Radiation Oncology, University of Lübeck, Lübeck, Germany; \\ ${ }^{6}$ Department of Respiratory Medicine, Graduate School of Medical Sciences, Kumamoto University, Kumamoto, Japan; ${ }^{7}$ Medical Oncology, IRCCS \\ Ospedale Sacro Cuore Don Calabria, Negrar di Valpolicella (VR), Italy; ${ }^{8}$ Medical Oncology Unit, Department of Human Pathology "G. Barresi”, \\ University of Messina, Messina, Italy; ${ }^{9}$ Department of Respiratory and Critical Care Medicine, Lung Cancer Treatment Center, West China \\ Hospital, Sichuan University, Chengdu, China; ${ }^{10}$ Precision Medicine Research Center, West China Hospital, Sichuan University, Chengdu, China \\ Contributions: (I) Conception and design: L Yang, Y Zhou, G Wang, Y Li, W Li; (II) Administrative support: Y Li, W Li; (III) Provision of study \\ materials or patients: None; (IV) Collection and assembly of data: G Wang, D Liu, B Chen, D Pu; (V) Data analysis and interpretation: L Yang, Y \\ Zhou, G Wang, D Liu, B Chen, D Pu; (VI) Manuscript writing: All authors; (VII) Final approval of manuscript: All authors.
}

\#These authors contributed equally to this work.

*These authors contributed equally to this work.

Correspondence to: Yalun Li. Department of Respiratory and Critical Care Medicine, Lung Cancer Treatment Center, West China Hospital, Sichuan University, Chengdu, China. Email: lunlunhx@qq.com; Weimin Li. Department of Respiratory and Critical Care Medicine, West China Hospital, Sichuan University, Chengdu, China. Email: weimin003@163.com.

Background: Combined small-cell lung cancer (CSCLC) refers to the simultaneous presence of small cell lung cancer (SCLC) and any subtype of the non-small cell lung cancer (NSCLC). This study aimed to explore the prognosis of CSCLC, NSCLC, and pure SCLC patients, and to develop a nomogram to estimate the overall survival (OS) for CSCLC patients.

Methods: Patients diagnosed with NSCLC, CSCLC, and pure SCLC between 2004 and 2015 were identified from the Surveillance Epidemiology and End Results (SEER) database. Survival analyses were performed by using the Kaplan Meier curves and Cox proportional hazards regression. All CSCLC patients were randomly split 7:3 into training and validation sets. A nomogram was developed by integrating all independent predictors for OS. The performance of the nomogram was determined by discrimination, calibration ability, clinical usefulness, and risk stratification ability.

Results: A total of 326,695 lung cancer patients, including 871 with CSCLC, 280,391 with NSCLC, and 45,433 with pure SCLC were enrolled. CSCLC was associated with worse survival compared with NSCLC both in the unmatched and matched cohorts. However, compared to pure SCLC, CSCLC was associated with significantly better survival in the unmatched cohorts only, while showed marginally non-significantly better survival after propensity score matching (PSM). For CSCLC, a nomogram was constructed for the 6-month, 1-year, and 3-year OS prediction by combining the independent risk factors, including age, gender, tumor, node, and metastasis stage, surgery, and chemotherapy. The nomogram showed good discrimination and calibration both in the training and validation sets, and better performance than the tumor-node-

^ ORCID: Lan Yang, 0000-0001-9112-4137; Yuwen Zhou, 0000-0002-3625-2854; Gang Wang, 0000-0002-5048-6606; Dan Liu, 00000001-6791-1704; Dan Pu, 0000-0001-7333-478X; Pierpaolo Correale, 0000-0003-2154-6734; Weimin Li, 0000-0003-0985-0311. 
metastasis staging system. Risk stratification analysis indicated that the nomogram scores efficiently divided CSCLC patients into low-, intermediate-, and high-risk groups $(\mathrm{P}<0.001)$.

Conclusions: CSCLC patients presented a significantly worse prognosis than patients with NSCLC, but comparable prognosis when compared with pure SCLC patients in the matched cohorts. In addition, we developed and validated a nomogram for predicting the 6-month, 1-year, and 3-year OS in CSCLC patients.

Keywords: Combined small cell lung cancer (CSCLC); nomogram; prognosis; propensity-score matching (PSM); the Surveillance Epidemiology and End Results (SEER)

Submitted Aug 26, 2021. Accepted for publication Nov 03, 2021.

doi: $10.21037 /$ tlcr-21-804

View this article at: https://dx.doi.org/10.21037/tlcr-21-804

\section{Introduction}

Small cell lung cancer (SCLC) represents a well-defined class of lung tissue-derivative malignancies showing a neuroendocrine pattern associated to a rapid growth, disposition to early metastasization and mortality $(1,2)$. The World Health Organization (WHO) histology classification divides SCLC into SCLC and combined SCLC (CSCLC), with the latter accounting for approximately $5-20 \%$ of total SCLC cases $(3,4)$. As a relatively infrequent subtype of SCLC, CSCLC refers to the simultaneous presence of SCLC histology and any subtype of the non-small cell lung cancer (NSCLC) histology. Except for the minimum requirement of $10 \%$ for large-cell neuroendocrine carcinoma components, CSCLC presents no restrictions on the amount of any other NSCLC components (5).

In this context, the prognosis and treatment of patients with CSCLC subset has seldom been investigated (6-10). Previous studies have reported that CSCLC and SCLC do not present any significant differences in term of clinical and pathologic features $(6,7)$. The latest European Society for Medical Oncology (ESMO) Clinical Practice Guideline does not significantly distinguish between the treatment of CSCLC and pure SCLC (5). For what concerns the prognosis of these patients, conflicting results have been reported by different studies. Some studies in fact detected a worse overall survival (OS) in patients with CSCLC compared with those diagnosed with a pure $\operatorname{SCLC}(8,9)$, while some studies have reported that CSCLC patients have better OS (11). A further population-based analysis reported better OS in CSCLC over pure SCLC patients only if diagnosed in the early stage of disease, while any difference in survival was lost for the advanced disease (7).

On the OS for patients with CSCLC, there is still a lack of prediction models for what concerns prognosis and risk stratification. Accurate estimation of prognosis at individual level is critical for either decision-making or engagement on an aggressive treatment guidance. We believe that the use of nomogram, a graphic depiction of model which integrate multiple variables, could provide reliable numerical predictions able to individualize the specific risk based on both patient and disease features (12). Therefore, we attempted to develop a nomogram based on prognostic model for CSCLC patients using the population-based Surveillance, Epidemiology, and End Results (SEER) database. We present the following article in accordance with the TRIPOD reporting checklist (available at https:// dx.doi.org/10.21037/tlcr-21-804).

\section{Methods}

\section{Patient selection}

SEER is an authoritative source for cancer statistics in the United States. The SEER program provides information on cancer statistics in an effort to reduce the cancer burden among the U.S. population. Information of patients histologically diagnosed with NSCLC, CSCLC, or pure SCLC between 2004 and 2015 were extracted from the SEER database. The exclusion criteria were as follows: (I) patients diagnosed only by autopsy or death certificate; (II) patients having at least one prior malignancy; and (III) patients with missing information concerning primary tumor $(\mathrm{T})$, regional lymph node $(\mathrm{N})$, or distant metastasis $(\mathrm{M})$ stage. The study was conducted according to the criteria set by the declaration of Helsinki (as revised in 2013).

\section{Study variables}

The extracted clinical information included age, gender, 
race, primary site (left upper lobe, left lower lobe, right upper lobe, right middle lobe, right lower lobe, main bronchus, or unspecific), tumor staging according to the Sixth American Joint Committee on Cancer (AJCC) TNM stage, surgery, radiation, and classic chemotherapy. OS was defined as the interval between cancer diagnosis and death resulting from any cause or the last follow-up for patients still alive. Lung cancer-specific survival (LCSS) was defined as the interval between cancer diagnosis and death from lung cancer.

\section{Statistical analysis}

We used descriptive statistics to summarize the baseline characteristics of the patients. Chi-squared tests were used to analyze the categorical variables. We used random 1:4 nearest-neighbor propensity score matching (PSM) without replacement to balance all baseline covariates between CSCLC and NSCLC, and between CSCLC and pure SCLC, respectively. OS and LCSS survival analyses were performed using the Kaplan-Meier method.

All enrolled CSCLC patients were further randomly split into the training and validation sets at a ratio of 7:3. For the training set, the independent prognostic factors of OS were determined using univariate and multivariate Cox proportional hazards regression models. Variables with $\mathrm{P}<0.05$ in the multivariable analyses were selected for the final nomogram development of predicting 6-month, 1-year, and 3-year OS for CSCLC patients.

The concordance index (C-index) and area under the receiver operator characteristic curve (AUC) were used to quantify discrimination. A calibration curve was drawn to assess the consistency between actual prognosis and predicted survival. Decision curve analysis (DCA) (13) was conducted to compare the benefits and improved performance of the nomogram and TNM staging system. According to the risk probability obtained from the nomogram, we determined the best cutoff points of survival probability using $\mathrm{X}$-tile software (version 3.6.1) and classified patients into three groups (low, intermediate-, and high-risk). The median OS of different risk groups was calculated by the Kaplan-Meier method.

A two-sided $\mathrm{P}$ value $<0.05$ was considered statistically significant. Data analyses were performed by the SPSS Statistics version 25 (IBM Corporation, Armonk, NY, USA) and RStudio version 1.4.1106 (RStudio, Boston, MA, USA).

\section{Results}

\section{Patient characteristics}

The patients' screening flowchart is summarized in Figure 1. A total of 326,695 lung cancer patients were included in the analysis. Of these, CSCLC, NSCLC and pure SCLC histology were respectively detected in $871,280,391$, and 45,433 patients (Table 1). There were statistically significantly more males than females in the CSCLC and NSCLC groups, while no statistically significant difference was detected in pure SCLC patients' group. We recorded a more advanced $\mathrm{T}, \mathrm{N}$, and $\mathrm{M}$ stages in patients with pure SCLC histology compared in sequence with patients with CSCLC and NSCLC.

Additionally, we recorded lower proportion of patients who did not receive surgery in pure SCLC compared with CSCLC and NSCLC histology. On the other hand, patients with CSCLC and pure SCLC tended to receive more frequently radiation than patients with NSCLC. The proportion of patients who underwent chemotherapy in pure SCLC, CSCLC, and NSCLC patients was $71.9 \%$, $64.9 \%$, and $45.7 \%$, respectively.

Throughout PSM analysis, these patients were matched 1:4 by age, gender, race, primary site, TNM stage, and treatment. All covariates were subsequently well balanced (Table S1) both in the 1:4 matched cohort of CSCLC $(n=871)$ and NSCLC $(n=3,484)$, and the 1:4 matched cohort of CSCLC ( $n=871)$ and pure SCLC $(n=3,366)$.

\section{Survival analysis of CSCLC and NSCLC}

For the cohorts before PSM, CSCLC patients presented a median OS of 10.00 months and a median LCSS of 11.00 months, whereas the median OS and LCSS of NSCLC patients were 12.00 and 14.00 months, respectively $(\mathrm{P}<0.001$; Figure 2A,2B).

After PSM, the median OS of CSCLC patients was 10.00 months, which was still poorer than the OS of the NSCLC patients (12.00 months; $\mathrm{P}<0.001$; Figure $2 C)$. The same trends were observed in the LCSS of the two groups, with the median LCSS for CSCLC and NSCLC patients being 11.00 and 14.00 months, respectively $(\mathrm{P}<0.001$; Figure 2D). In the Cox proportional hazards regression of matched CSCLC and NSCLC patients, NSCLC histology was correlated with better OS, with the hazard ratio (HR) for OS being 0.77 [95\% confidence interval (CI): 0.71-0.83; $\mathrm{P}<0.001$; Table 2] and that for LCSS being 0.73 (95\% CI $0.67-0.79 ; \mathrm{P}<0.001$; Table S2). 


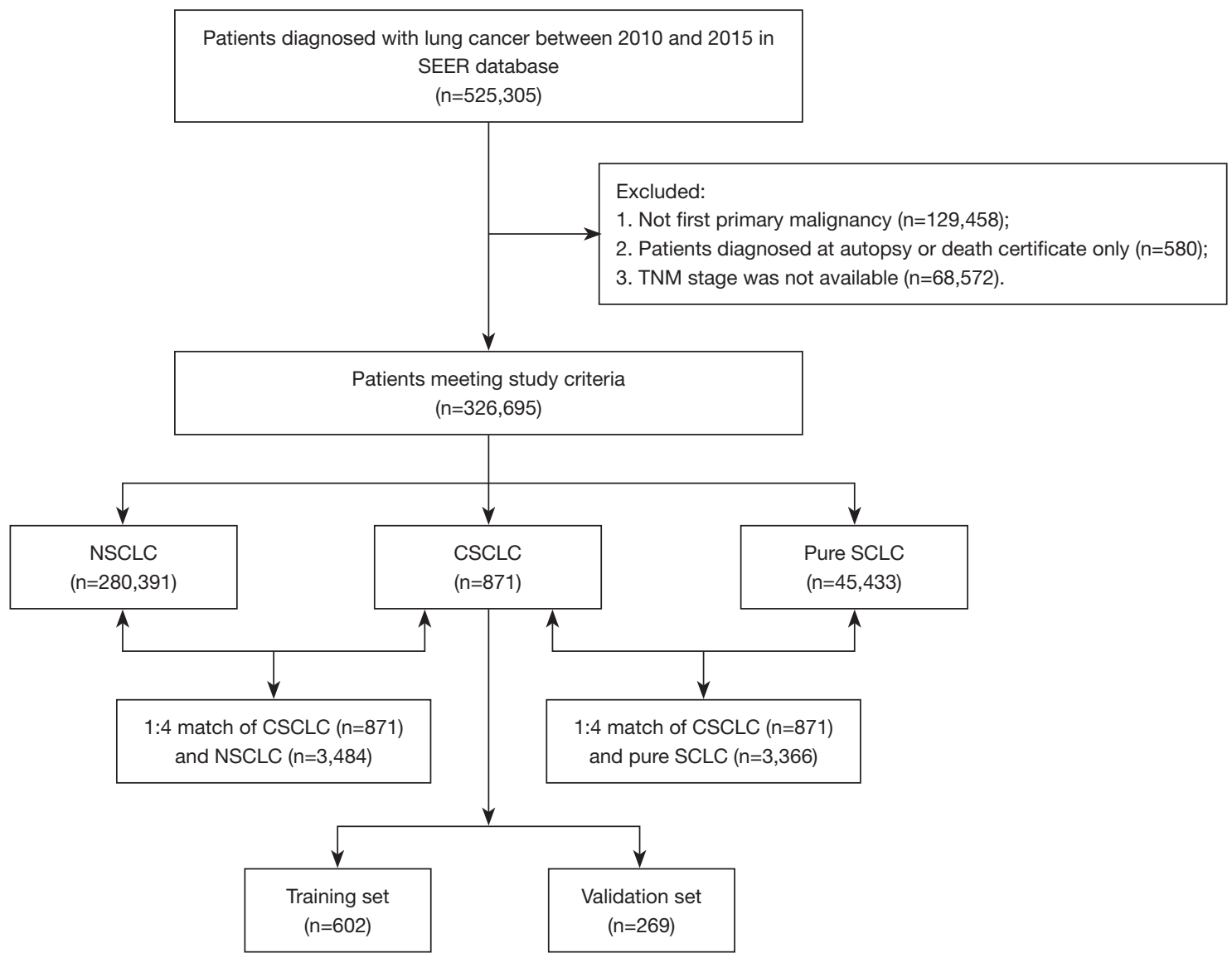

Figure 1 Patient selection scheme for the study. SEER, Surveillance Epidemiology and End Results; NSCLC, non-small cell lung cancer; CSCLC, combined small cell lung cancer; SCLC, small cell lung cancer.

Table 1 Demographics and clinicopathologic characteristics of patients with CSCLC, NSCLC, and pure SCLC

\begin{tabular}{|c|c|c|c|c|c|c|c|c|}
\hline Characteristics & \multicolumn{2}{|c|}{$\operatorname{CSCLC}(n=871)$} & \multicolumn{2}{|c|}{$\operatorname{NSCLC}(n=280,391)$} & $P_{1}$ value & \multicolumn{2}{|c|}{ Pure SCLC $(n=45,433)$} & $\mathrm{P}_{2}$ value \\
\hline Age (years) & & & & & 0.066 & & & 0.298 \\
\hline$\leq 60$ & 229 & 26.3 & 71,494 & 25.5 & & 12,775 & 28.1 & \\
\hline $60-70$ & 305 & 35.0 & 89,909 & 32.1 & & 16,162 & 35.6 & \\
\hline Gender & & & & & 0.099 & & & $<0.001$ \\
\hline Female & 378 & 43.4 & 129,512 & 46.2 & & 22,700 & 50.0 & \\
\hline Male & 493 & 56.6 & 150,879 & 53.8 & & 22,733 & 50.0 & \\
\hline Race & & & & & $<0.001$ & & & 0.003 \\
\hline Other & 35 & 4.0 & 21,244 & 7.6 & & 1,892 & 4.2 & \\
\hline
\end{tabular}

Table 1 (continued) 
Table 1 (continued)

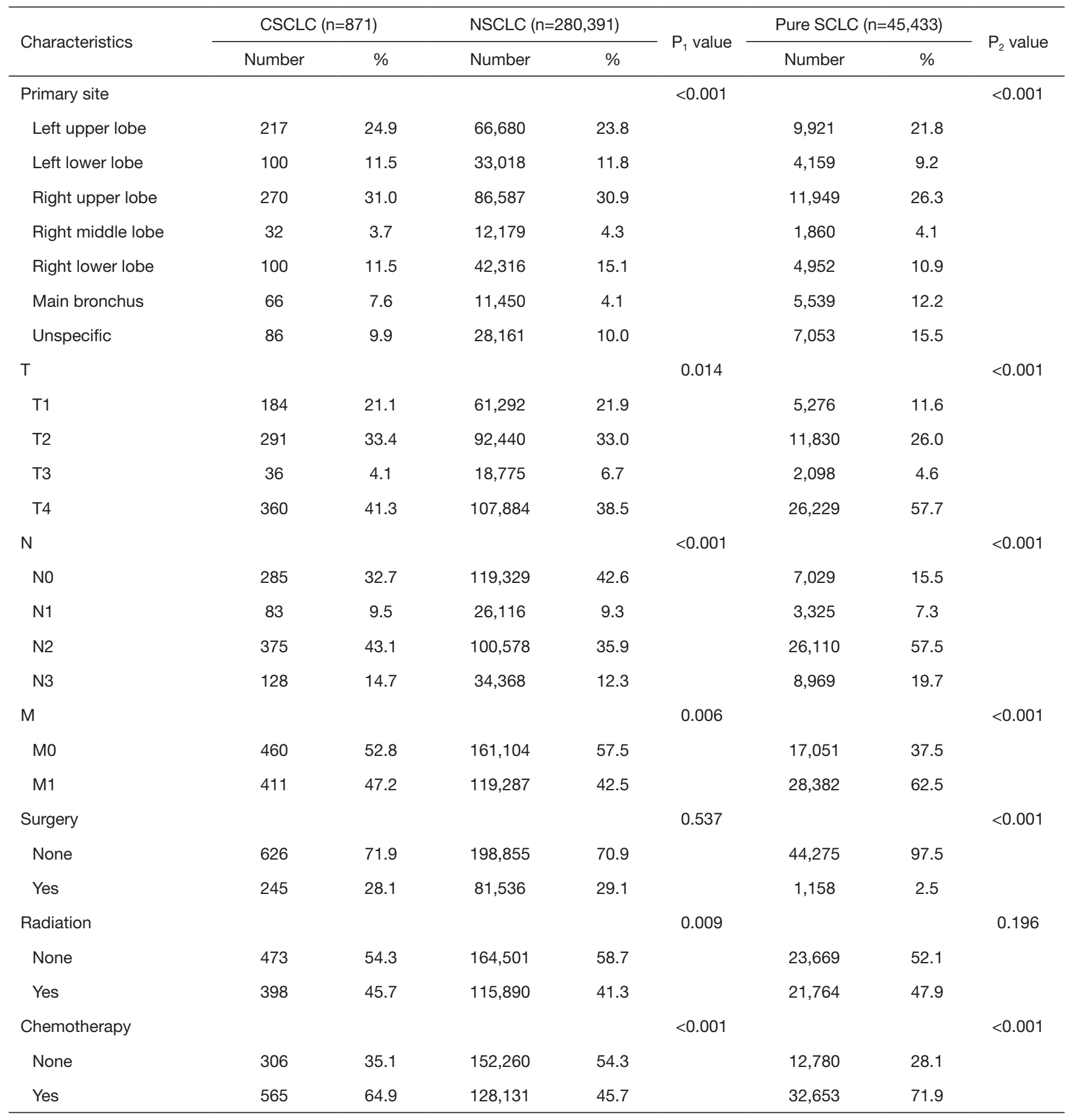

CSCLC, combined small cell lung cancer; NSCLC, non-small cell lung cancer; SCLC, small cell lung cancer. 

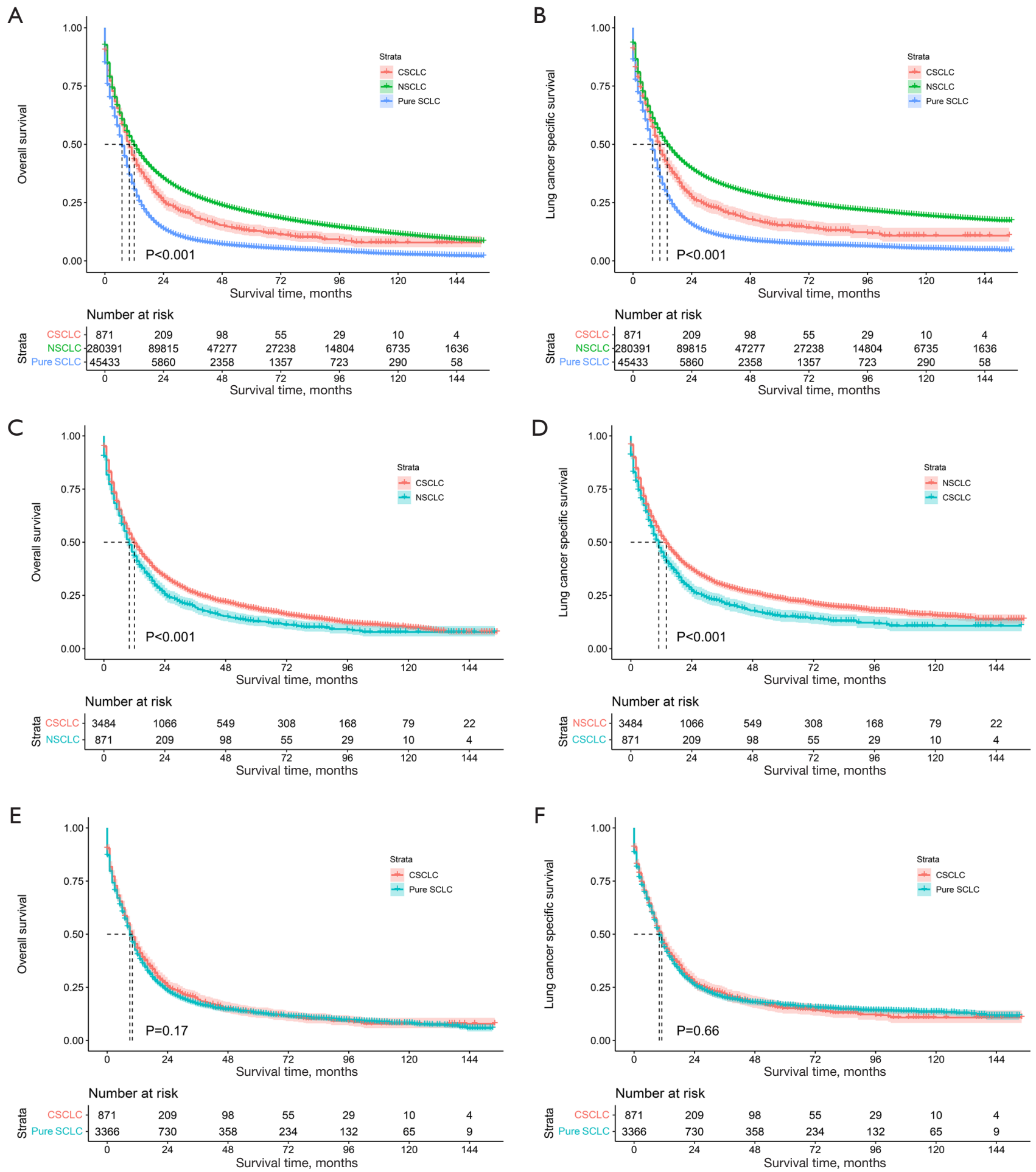

Figure 2 Kaplan-Meier curves of patients with CSCLC, NSCLC, and pure SCLC in unmatched and matched cohorts. (A,B) Before PSM, OS, and LCSS in patients with CSCLC, NSCLC, and pure SCLC. (C,D). After PSM, OS, and LCSS in CSCLC 1:4 matched with NSCLC cohorts. (E,F). After PSM, OS, and LCSS in CSCLC 1:4 matched with pure SCLC cohorts. NSCLC, non-small cell lung cancer; CSCLC, combined small cell lung cancer; SCLC, small cell lung cancer; PSM, propensity score matching; OS, overall survival; LCSS, lung cancerspecific survival. 
Table 2 Univariate and multivariate Cox analyses of OS for NSCLC and CSCLC patients in unmatched and matched cohorts

\begin{tabular}{|c|c|c|c|c|c|c|c|c|c|c|c|c|}
\hline \multirow{3}{*}{ Characteristics } & \multicolumn{6}{|c|}{$\operatorname{CSCLC}(n=871)$ and NSCLC $(n=280,391)$} & \multicolumn{6}{|c|}{$1: 4$ match of CSCLC $(n=871)$ and NSCLC $(n=3,484)$} \\
\hline & \multicolumn{3}{|c|}{ Univariable } & \multicolumn{3}{|c|}{ Multivariable } & \multicolumn{3}{|c|}{ Univariable } & \multicolumn{3}{|c|}{ Multivariable } \\
\hline & $\mathrm{HR}$ & $95 \% \mathrm{Cl}$ & $\mathrm{P}$ & $\mathrm{HR}$ & $95 \% \mathrm{Cl}$ & $\mathrm{P}$ & $\mathrm{HR}$ & $95 \% \mathrm{Cl}$ & $\mathrm{P}$ & $\mathrm{HR}$ & $95 \% \mathrm{Cl}$ & $\mathrm{P}$ \\
\hline \multicolumn{13}{|l|}{ Age (years) } \\
\hline$\leq 60$ & 1 & & & 1 & & & 1 & & & 1 & & \\
\hline$>70$ & 1.28 & $1.27-1.30$ & $<0.001$ & 1.30 & $1.28-1.31$ & $<0.001$ & 1.34 & $1.23-1.45$ & $<0.001$ & 1.32 & $1.21-1.44$ & $<0.001$ \\
\hline \multicolumn{13}{|l|}{ Gender } \\
\hline Female & 1 & & & 1 & & & 1 & & & 1 & & \\
\hline Male & 1.29 & $1.27-1.30$ & $<0.001$ & 1.24 & $1.23-1.25$ & $<0.001$ & 1.30 & $1.22-1.39$ & $<0.001$ & 1.30 & $1.21-1.39$ & $<0.001$ \\
\hline Black & 1.13 & $1.11-1.14$ & $<0.001$ & 0.99 & $0.98-1.00$ & 0.144 & 1.13 & $1.02-1.24$ & 0.016 & 0.97 & $0.88-1.07$ & 0.516 \\
\hline Other & 0.89 & $0.87-0.90$ & $<0.001$ & 0.75 & $0.74-0.76$ & $<0.001$ & 0.94 & $0.79-1.11$ & 0.444 & 0.69 & $0.58-0.81$ & $<0.001$ \\
\hline \multicolumn{13}{|l|}{ Primary site } \\
\hline Left upper lobe & 1 & & & 1 & & & 1 & & & 1 & & \\
\hline Left lower lobe & 1.00 & $0.98-1.01$ & 0.598 & 1.03 & $1.02-1.05$ & $<0.001$ & 1.00 & $0.89-1.12$ & 0.983 & 1.00 & $0.89-1.13$ & 0.945 \\
\hline Right upper lobe & 0.99 & $0.99-1.00$ & 0.059 & 0.98 & $0.97-0.99$ & 0.001 & 0.99 & $0.90-1.08$ & 0.989 & 0.92 & $0.84-1.00$ & 0.055 \\
\hline Right middle lobe & 0.96 & $0.94-0.98$ & $<0.001$ & 0.98 & $0.96-1.01$ & 0.144 & 1.14 & $0.95-1.35$ & 0.150 & 1.14 & $0.96-1.36$ & 0.128 \\
\hline Right lower lobe & 1.04 & $1.02-1.05$ & $<0.001$ & 1.05 & $1.04-1.07$ & $<0.001$ & 1.13 & $1.00-1.27$ & 0.053 & 1.13 & $1.00-1.27$ & 0.051 \\
\hline T3 & 2.37 & $2.33-2.42$ & $<0.001$ & 1.88 & $1.84-1.92$ & $<0.001$ & 1.99 & $1.68-2.37$ & $<0.001$ & 1.70 & $1.42-2.02$ & $<0.001$ \\
\hline $\mathrm{T} 4$ & 3.39 & $3.35-3.43$ & $<0.001$ & 1.90 & $1.87-1.93$ & $<0.001$ & 2.61 & $2.37-2.86$ & $<0.001$ & 1.77 & $1.60-1.97$ & $<0.001$ \\
\hline \multicolumn{13}{|l|}{$\mathrm{N}$} \\
\hline No & 1 & & & 1 & & & 1 & & & 1 & & \\
\hline $\mathrm{N} 1$ & 1.46 & $1.44-1.48$ & $<0.001$ & 1.41 & $1.39-1.43$ & $<0.001$ & 1.24 & $1.09-1.40$ & 0.001 & 1.33 & $1.17-1.51$ & $<0.001$ \\
\hline $\mathrm{N} 2$ & 2.35 & $2.33-2.38$ & $<0.001$ & 1.54 & $1.52-1.56$ & $<0.001$ & 2.18 & $2.01-2.36$ & $<0.001$ & 1.62 & $1.48-1.77$ & $<0.001$ \\
\hline N3 & 2.71 & $2.68-2.75$ & $<0.001$ & 1.55 & $1.52-1.57$ & $<0.001$ & 2.46 & $2.22-2.73$ & $<0.001$ & 1.53 & $1.36-1.72$ & $<0.001$ \\
\hline \multicolumn{13}{|l|}{ M } \\
\hline Mo & 1 & & & 1 & & & 1 & & & 1 & & \\
\hline M1 & 2.97 & 2.94-2.99 & $<0.001$ & 1.80 & $1.78-1.82$ & $<0.001$ & 2.78 & $2.59-2.97$ & $<0.001$ & 1.86 & $1.72-2.01$ & $<0.001$ \\
\hline
\end{tabular}

Table 2 (continued) 
Table 2 (continued)

\begin{tabular}{|c|c|c|c|c|c|c|c|c|c|c|c|c|}
\hline \multirow{3}{*}{ Characteristics } & \multicolumn{6}{|c|}{$\operatorname{CSCLC}(n=871)$ and NSCLC $(n=280,391)$} & \multicolumn{6}{|c|}{$1: 4$ match of CSCLC $(n=871)$ and NSCLC $(n=3,484)$} \\
\hline & \multicolumn{3}{|c|}{ Univariable } & \multicolumn{3}{|c|}{ Multivariable } & \multicolumn{3}{|c|}{ Univariable } & \multicolumn{3}{|c|}{ Multivariable } \\
\hline & $\mathrm{HR}$ & $95 \% \mathrm{Cl}$ & $\mathrm{P}$ & $\mathrm{HR}$ & $95 \% \mathrm{Cl}$ & $\mathrm{P}$ & $\mathrm{HR}$ & $95 \% \mathrm{Cl}$ & $\mathrm{P}$ & $\mathrm{HR}$ & $95 \% \mathrm{Cl}$ & $\mathrm{P}$ \\
\hline \multicolumn{13}{|l|}{ Histology } \\
\hline CSCLC & 1 & & & 1 & & & 1 & & & 1 & & \\
\hline \multicolumn{13}{|l|}{ Surgery } \\
\hline None & 1 & & & 1 & & & 1 & & & 1 & & \\
\hline Yes & 0.22 & $0.22-0.23$ & $<0.001$ & 0.31 & $0.30-.0 .31$ & $<0.001$ & 0.26 & $0.24-0.29$ & $<0.001$ & 0.36 & $0.33-0.40$ & $<0.001$ \\
\hline \multicolumn{13}{|l|}{ Radiation } \\
\hline \multicolumn{13}{|l|}{ Chemotherapy } \\
\hline None & 1 & & & 1 & & & 1 & & & 1 & & \\
\hline Yes & 1.02 & $1.01-1.03$ & $<0.001$ & 0.51 & $0.51-0.52$ & $<0.001$ & 0.97 & $0.90-1.04$ & 0.335 & 0.48 & $0.45-0.52$ & $<0.001$ \\
\hline
\end{tabular}

OS, overall survival; CSCLC, combined small cell lung cancer; NSCLC, non-small cell lung cancer; $\mathrm{HR}$, hazard ratio; Cl, confidence interval.

\section{Survival analysis of CSCLC and pure SCLC}

Before PSM, the median OS and LCSS observed in CSCLC patients were longer than those recorded in pure SCLC patients (OS: 10.00 vs. 7.00 months; $\mathrm{P}<0.001$; LCSS: 11.00 vs. 8.00 months; $\mathrm{P}<0.001$; Figure $2 A, 2 B)$.

However, in matched CSCLC and pure SCLC patients, there were marginally non-significant differences in OS (median: CSCLC, 10.00 vs. pure SCLC, 9.00 months; $\mathrm{P}=0.17$; Figure $2 E$ ) and LCSS (median: CSCLC, 11.00 vs. pure SCLC, 10.00 months; $\mathrm{P}=0.66$; Figure $2 F$ ). In Cox regression analyses, pure SCLC was not associated with statistically worse OS [hazard ratio (HR) 1.06; $95 \%$ CI: 0.97-1.14; $\mathrm{P}=0.185$; Table 3] and LCSS (HR 1.02; 95\% CI: 0.94-1.11; $\mathrm{P}=0.669$; Table S3).

\section{Independent prognostic factors for OS of CSCLC patients}

A total of 871 CSCLC patients were randomly assigned to the training set $(n=602)$ and the validation set $(n=269)$ in a $7: 3$ ratio. Table $\mathrm{S} 4$ shows the clinicopathologic characteristics of CSCLC patients in the training and validation data sets. Except for more younger patients, more $\mathrm{T} 4$ stage patients in the training set (aged $\leq 60$ years: $28.9 \%$ vs. $20.4 \%$; T4: $43.5 \%$ vs. $36.4 \%$ ), there was no significant difference observed between the two data sets.

Univariate and multivariate Cox regression analyses were performed on the training data set (Table 4) and revealed that age, gender, primary site, TNM stage, surgery, and chemotherapy were all significantly correlated to OS. These meaningful factors were selected for further multivariate analyses. Although significant in univariate analysis, primary site did not remain significant in the multivariate analysis. Therefore, seven independent prognostic factors were included in the final nomogram, including age, gender, $\mathrm{T}$, $\mathrm{N}$, and $\mathrm{M}$ stage, surgery, and chemotherapy. It was recorded that age older than 70 years at diagnosis (HR 1.59; 95\% CI: 1.27-1.99; $\mathrm{P}<0.001$ ), N3 (HR 1.95; 95\% CI: 1.42-2.67; $\mathrm{P}<0.001)$, and M1 (HR 1.82; 95\% CI: 1.49-2.23; $\mathrm{P}<0.001)$ had the largest negative impact on the OS. Surgery (HR 0.46, $95 \%$ CI: $0.36-0.58 ; \mathrm{P}<0.001)$ and chemotherapy (HR $0.41,95 \%$ CI: $0.33-0.50 ; \mathrm{P}<0.001)$ were associated with favorable OS.

\section{Development of the nomogram}

The nomogram incorporating these seven predictors was constructed to predict the 6-month, 1-year, and 3-year survival probability in CSCLC patients (Figure 3). The 
Table 3 Univariate and multivariate Cox analyses of OS for NSCLC and pure SCLC patients in unmatched and matched cohorts

\begin{tabular}{|c|c|c|c|c|c|c|c|c|c|c|c|c|}
\hline \multirow{3}{*}{ Characteristics } & \multicolumn{6}{|c|}{$\operatorname{CSCLC}(n=871)$ and pure SCLC $(n=45,433)$} & \multicolumn{6}{|c|}{ 1:4 match of CSCLC $(n=871)$ and pure SCLC $(n=3,366)$} \\
\hline & \multicolumn{3}{|c|}{ Univariable } & \multicolumn{3}{|c|}{ Multivariable } & \multicolumn{3}{|c|}{ Univariable } & \multicolumn{3}{|c|}{ Multivariable } \\
\hline & $\mathrm{HR}$ & $95 \% \mathrm{Cl}$ & $\mathrm{P}$ & $\mathrm{HR}$ & $95 \% \mathrm{Cl}$ & $\mathrm{P}$ & $\mathrm{HR}$ & $95 \% \mathrm{Cl}$ & $\mathrm{P}$ & $\mathrm{HR}$ & $95 \% \mathrm{Cl}$ & $\mathrm{P}$ \\
\hline \multicolumn{13}{|l|}{ Age (years) } \\
\hline$\leq 60$ & 1 & & & 1 & & & 1 & & & 1 & & \\
\hline$>70$ & 1.60 & $1.56-1.64$ & $<0.001$ & 1.41 & $1.37-1.44$ & $<0.001$ & 1.55 & $1.43-1.68$ & $<0.001$ & 1.52 & $1.40-1.66$ & $<0.001$ \\
\hline \multicolumn{13}{|l|}{ Gender } \\
\hline Female & 1 & & & 1 & & & 1 & & & 1 & & \\
\hline Male & 1.18 & $1.16-1.20$ & $<0.001$ & 1.16 & $1.14-1.18$ & $<0.001$ & 1.38 & $1.29-1.47$ & $<0.001$ & 1.31 & $1.23-1.40$ & $<0.001$ \\
\hline Black & 0.93 & $0.90-0.97$ & $<0.001$ & 0.94 & $0.91-0.97$ & $<0.001$ & 1.11 & $1.01-1.23$ & 0.032 & 1.02 & $0.93-1.13$ & 0.646 \\
\hline Other & 0.96 & $0.91-1.00$ & 0.061 & 0.91 & $0.87-0.95$ & $<0.001$ & 1.00 & $0.85-1.18$ & 0.985 & 0.73 & $0.62-0.86$ & $<0.001$ \\
\hline \multicolumn{13}{|l|}{ Primary site } \\
\hline Left upper lobe & 1 & & & 1 & & & 1 & & & 1 & & \\
\hline Left lower lobe & 1.06 & $1.02-1.10$ & 0.004 & 1.03 & $0.99-1.07$ & 0.112 & 0.95 & $0.85-1.07$ & 0.411 & 1.03 & $0.92-1.16$ & 0.590 \\
\hline Right upper lobe & 0.98 & $0.96-1.01$ & 0.231 & 1.00 & $0.97-1.03$ & 0.881 & 0.94 & $0.86-1.03$ & 0.183 & 0.93 & $0.85-1.02$ & 0.130 \\
\hline Right middle lobe & 0.99 & $0.94-1.04$ & 0.638 & 0.99 & $0.94-1.04$ & 0.639 & 0.87 & $0.73-1.04$ & 0.137 & 0.82 & $0.69-0.98$ & 0.031 \\
\hline Right lower lobe & 1.08 & $1.04-1.12$ & $<0.001$ & 1.04 & $1.01-1.08$ & 0.026 & 1.00 & $0.89-1.12$ & 0.983 & 1.07 & $0.95-1.21$ & 0.241 \\
\hline T3 & 1.47 & $1.40-1.55$ & $<0.001$ & 1.36 & $1.29-1.43$ & $<0.001$ & 2.15 & $1.82-2.54$ & $<0.001$ & 1.54 & $1.29-1.83$ & $<0.001$ \\
\hline $\mathrm{T} 4$ & 1.70 & $1.65-1.76$ & $<0.001$ & 1.43 & $1.39-1.48$ & $<0.001$ & 2.64 & $2.41-2.90$ & $<0.001$ & 1.62 & $1.46-1.79$ & $<0.001$ \\
\hline \multicolumn{13}{|l|}{$\mathrm{N}$} \\
\hline No & 1 & & & 1 & & & 1 & & & 1 & & \\
\hline $\mathrm{N} 1$ & 1.10 & $1.05-1.14$ & $<0.001$ & 1.14 & $1.09-1.19$ & $<0.001$ & 1.33 & $1.17-1.51$ & $<0.001$ & 1.38 & $1.22-1.57$ & $<0.001$ \\
\hline $\mathrm{N} 2$ & 1.39 & $1.35-1.43$ & $<0.001$ & 1.31 & $1.27-1.35$ & $<0.001$ & 2.07 & $1.91-2.24$ & $<0.001$ & 1.52 & $1.39-1.66$ & $<0.001$ \\
\hline N3 & 1.47 & $1.42-1.52$ & $<0.001$ & 1.34 & $1.29-1.38$ & $<0.001$ & 2.20 & $1.99-2.44$ & $<0.001$ & 1.36 & $1.22-1.53$ & $<0.001$ \\
\hline \multicolumn{13}{|l|}{ M } \\
\hline Mo & 1 & & & 1 & & & 1 & & & 1 & & \\
\hline M1 & 2.13 & $2.08-2.17$ & $<0.001$ & 1.78 & $1.74-1.82$ & $<0.001$ & 2.94 & $2.74-3.15$ & $<0.001$ & 2.02 & $1.88-2.18$ & $<0.001$ \\
\hline
\end{tabular}

Table 3 (continued) 
Table 3 (continued)

\begin{tabular}{|c|c|c|c|c|c|c|c|c|c|c|c|c|}
\hline \multirow{2}{*}{ Characteristics } & \multicolumn{6}{|c|}{$\operatorname{CSCLC~}(n=871)$ and pure SCLC $(n=45,433)$} & \multicolumn{6}{|c|}{$1: 4$ match of CSCLC $(n=871)$ and pure SCLC $(n=3,366)$} \\
\hline & HR & $95 \% \mathrm{Cl}$ & $\mathrm{P}$ & HR & $95 \% \mathrm{Cl}$ & $\mathrm{P}$ & HR & $95 \% \mathrm{Cl}$ & $\mathrm{P}$ & $\mathrm{HR}$ & $95 \% \mathrm{Cl}$ & $\mathrm{P}$ \\
\hline \multicolumn{13}{|l|}{ Histology } \\
\hline CSCLC & 1 & & & 1 & & & 1 & & & & & \\
\hline \multicolumn{13}{|l|}{ Surgery } \\
\hline None & 1 & & & 1 & & & 1 & & & 1 & & \\
\hline Yes & 0.38 & $0.36-0.41$ & $<0.001$ & 0.44 & $0.42-0.48$ & $<0.001$ & 0.36 & $0.33-0.39$ & $<0.001$ & 0.51 & $0.46-0.56$ & $<0.001$ \\
\hline \multicolumn{13}{|l|}{ Radiation } \\
\hline \multicolumn{13}{|l|}{ Chemotherapy } \\
\hline None & 1 & & & 1 & & & 1 & & & 1 & & \\
\hline Yes & 0.36 & $0.36-0.37$ & $<0.001$ & 0.39 & $0.38-0.40$ & $<0.001$ & 0.58 & $0.54-0.62$ & $<0.001$ & 0.51 & $0.47-0.55$ & $<0.001$ \\
\hline
\end{tabular}

OS, overall survival; CSCLC, combined small cell lung cancer; SCLC, small cell lung cancer; HR, hazard ratio; Cl, confidence interval.

Table 4 Univariate and multivariate Cox analyses in CSCLC patients

\begin{tabular}{|c|c|c|c|c|c|c|}
\hline Characteristics & \multicolumn{3}{|c|}{ Univariable } & \multicolumn{3}{|c|}{ Multivariable } \\
\hline \multicolumn{7}{|l|}{ Age (years) } \\
\hline$\leq 60$ & 1 & & & 1 & & \\
\hline $60-70$ & 1.22 & $0.98-1.52$ & 0.083 & 1.30 & $1.04-1.64$ & 0.023 \\
\hline \multicolumn{7}{|l|}{ Gender } \\
\hline Female & 1 & & & 1 & & \\
\hline Male & 1.33 & $1.12-1.58$ & 0.001 & 1.24 & $1.03-1.48$ & 0.022 \\
\hline \multicolumn{7}{|l|}{ Race } \\
\hline Other & 1.23 & $0.75-2.03$ & 0.411 & & & \\
\hline
\end{tabular}

Table 4 (continued) 
Table 4 (continued)

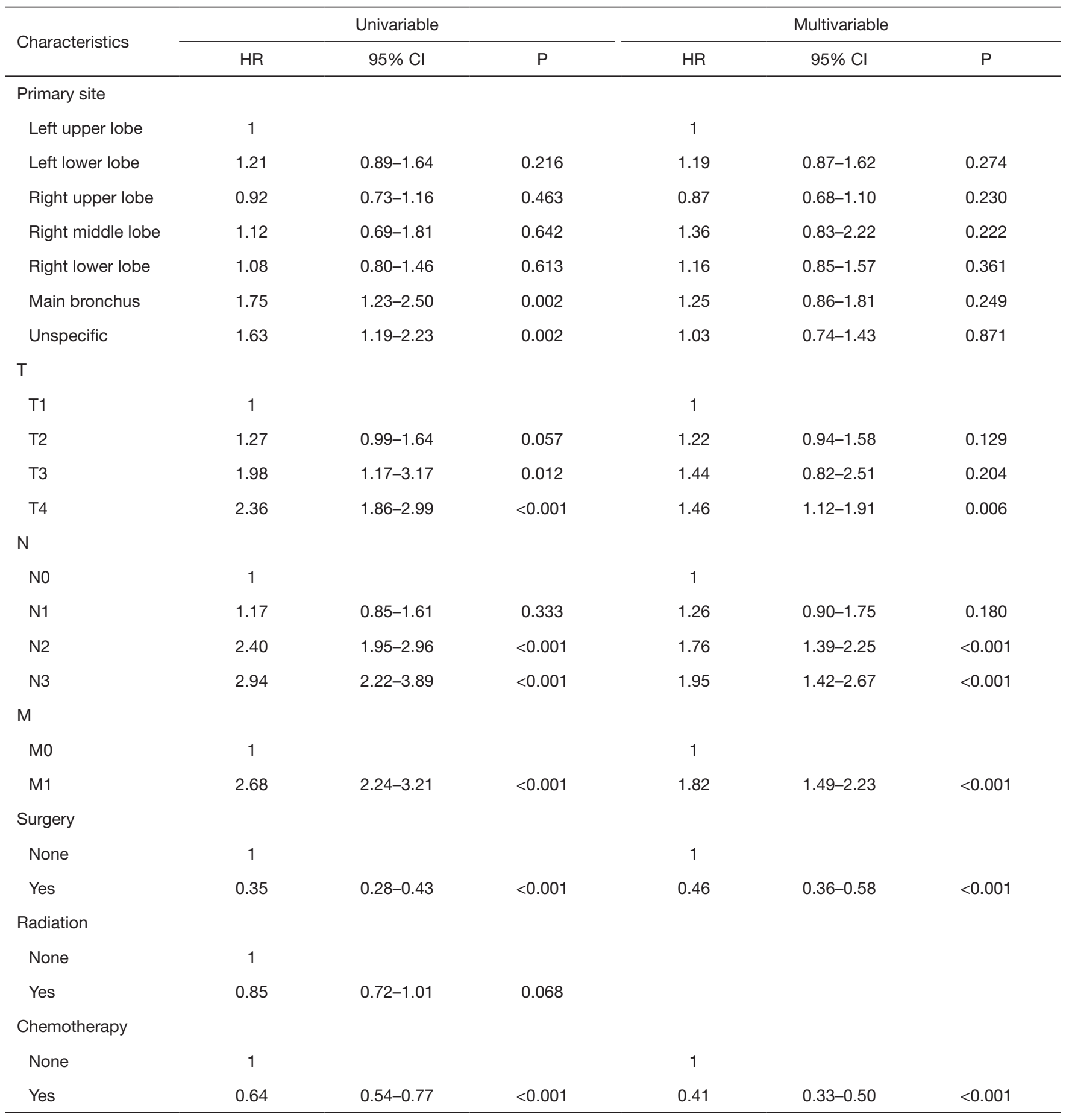

CSCLC, combined small cell lung cancer; HR, hazard ratio; $\mathrm{Cl}$, confidence interval.

online calculator based on our nomogram can be found at https://combined-small-cell-lung-cancer.shinyapps.io/ DynNomapp/.

\section{Calibration and validation of the nomogram}

The predictive accuracy as measured by the C-index was 0.76 in the validation cohort, which was similar to that 


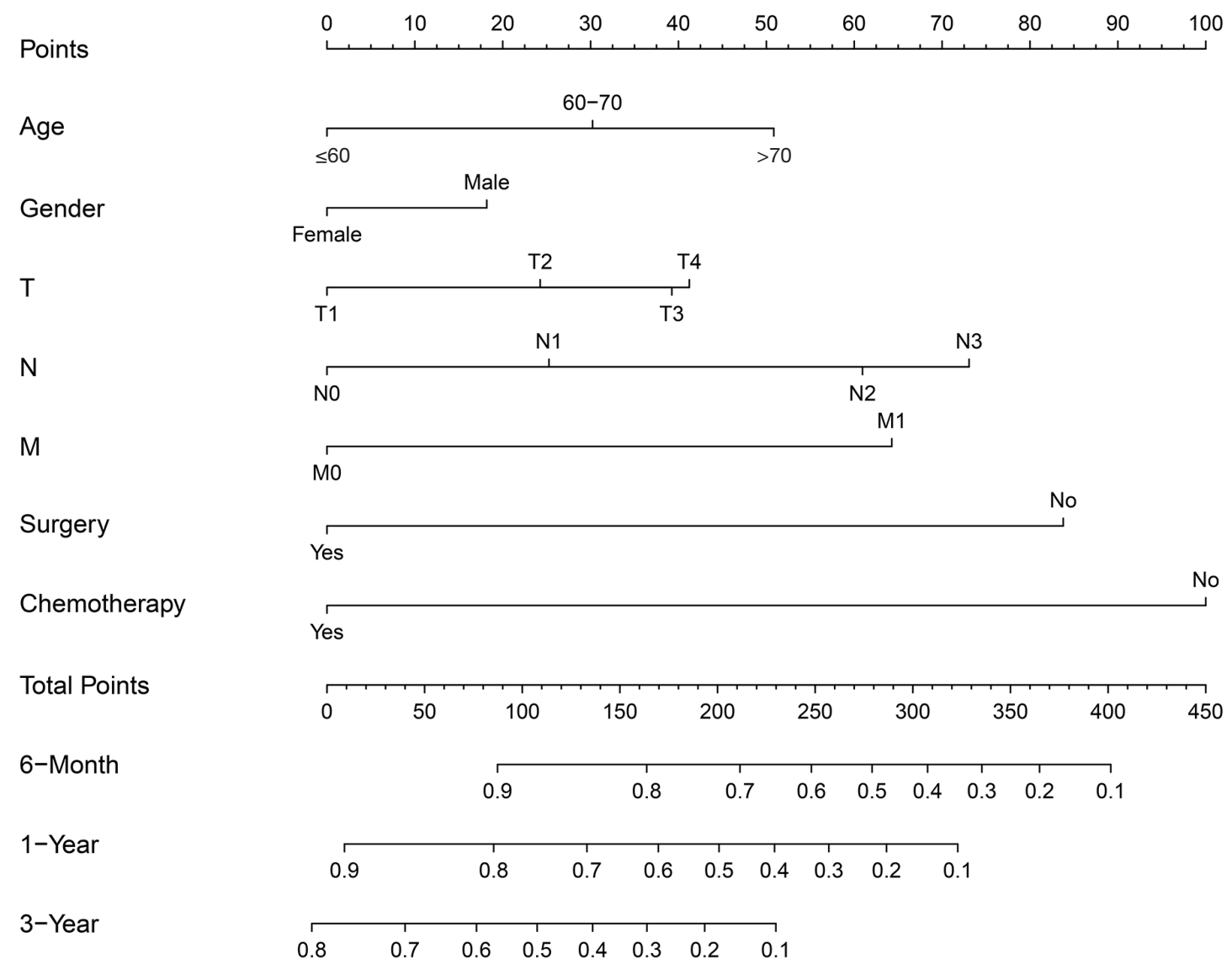

Figure 3 The nomogram model to predict the 6-month, 1-year, 3-year survival probability in CSCLC patients. CSCLC, combined small cell lung cancer.

observed in the training cohort of 0.76 . The favorable calibration of the nomogram was observed both in the training and validation sets, with good correlations between predicted and observed survival proportion at three different time points (Figure 4).

Compared to the TNM stage, the nomogram presented an improved AUC at 6 months, 1 year, and 3 years $(6$ months: $84.6 \%$ vs. $71.6 \%$; 1 year: $82.1 \%$ vs. $74.1 \%$; 3 years: $81.1 \%$ vs. $78.7 \%$; Figure S1A-S1C).

The DCA analyses comparing the clinical utility of the nomogram and the TNM staging system at 6 months, 1 year, and 3 years are displayed in Figure S1D-S1F). The nomogram yielded more clinical net benefit than the TNM stage at each time point.

\section{Risk stratification system}

Based on the total points calculated by the nomogram, we divided all patients into three risk groups with the optimal cutoff values being determined by X-tile software: low risk (less than or equal to 268), intermediate risk (268-340), and high risk (more than 340; Figure S2). The median OS of the three risk groups were $16.00,6.00$, and 1.00 months with the 3 -year OS rates of $27.8 \%, 7 \%$, and $0.7 \%$, respectively $(\mathrm{P}<0.001$; Figure $\mathrm{S} 3)$.

\section{Discussion}

Considering the infrequent detection of CSCLC histology among lung cancer diagnoses, this particular subtype has attracted limited attention by the scientific community, with few controversial results for what concerns the prognosis of these patients (8-11). Furthermore, most of the relevant studies relied on small and unbalanced statistical sample sizes, which limited the reliability of the findings to some extent. In the latest published study 
A

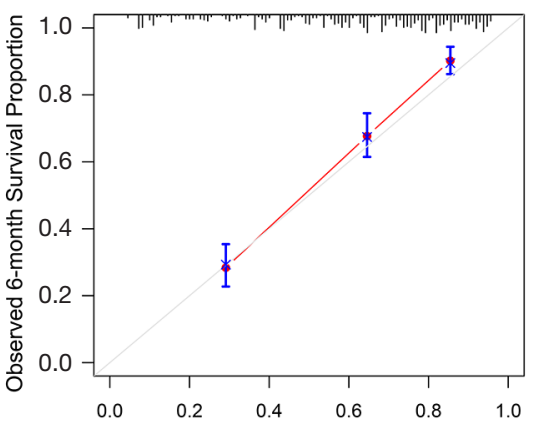

Nomogram-predicted probability of 6-month survival

D

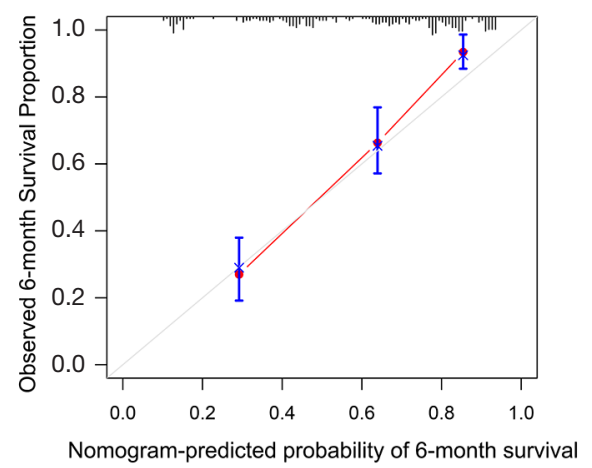

B

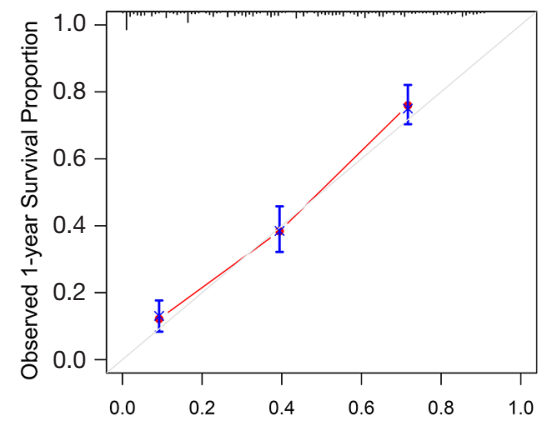

Nomogram-predicted probability of 1 -year survival

E

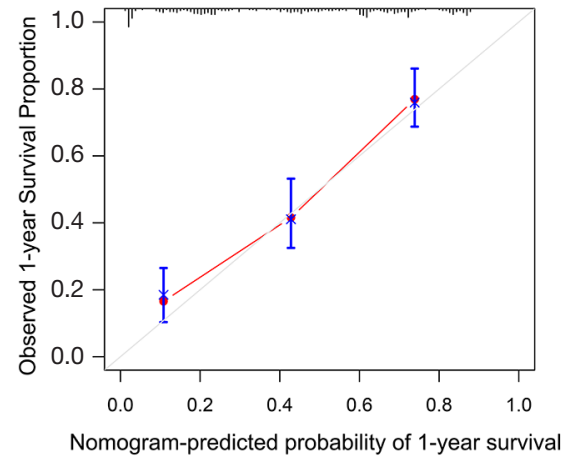

C

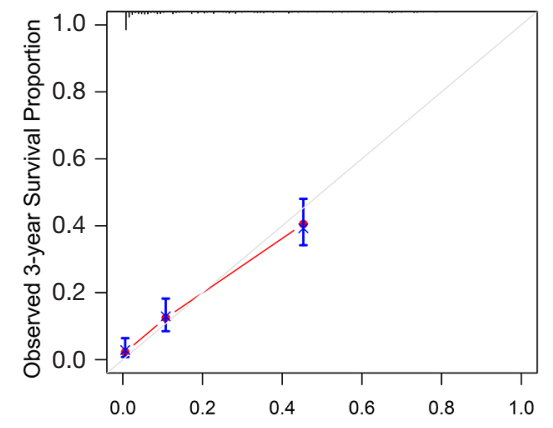

Nomogram-predicted probability of 3-year survival

F

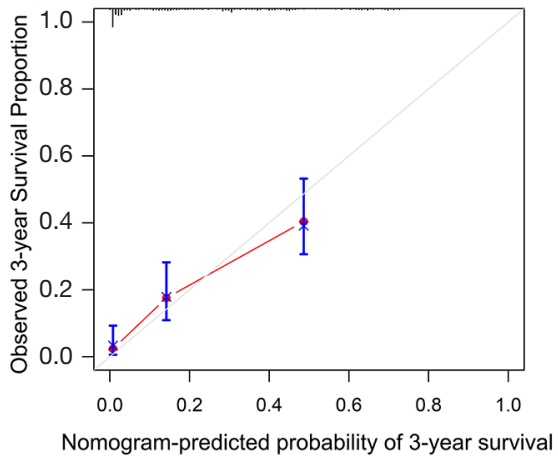

Figure 4 Nomogram calibration curves for predicting OS at (A) 6 months, (B) 1 year, and (C) 3 years in the training data set; and (D) 6 months, (E) 1 year, and (F) 3 years in the validation data set. OS, overall survival.

by Zhang et al. (8) with 52 CSCLC patients and 272 pure SCLC patients, they found patients with CSCLC had comparable clinicopathologic characteristics, but greater prognosis than those with SCLC. Our study is the largest PSM retrospective study to date on the prognosis between CSCLC, NSCLC, and pure SCLC patients. We demonstrated that CSCLC patients exhibited significantly worse OS and LCSS than NSCLC patients, but comparable prognosis to that of pure SCLC patients.

In addition, we identified the key prognostic factors of CSCLC patients and constructed the first comprehensive nomogram to provide the personalized, reasonably accurate prediction of the OS at 6 months, 1 year, and 3 years. The nomogram demonstrated good discrimination and calibration both in the training and validation cohorts.

For SCLC patients, the TNM staging system was widely used for the risk stratification, which was superior to the classic dichotomous staging system of the Veterans Administration Lung Study Group (VALSG) (14). Relative to the AJCC TNM staging system, our nomogram performed better at 6 months, 1 year, and 3 years. Future studies are needed to validate our results. In addition, we developed an online calculator of our nomogram, which could serve as a rapid and user-friendly adjunct tool for clinicians in the clinic.

SCLC predominantly occurred in elderly patients. Given the aging population in the USA, the proportion of patients older than 70 years among all SCLC cases increased from $23 \%$ in 1975 to $44 \%$ in 2010 (15). A similar trend was also observed for the SCLC patients in China (16). With the rising incidence in CSCLC (4), elderly patients with CSCLC will require more attention in the future. Risk stratification plays an essential role in the treatment of CSCLC patients. In our nomogram, we included age in the risk-stratification model, which may help clinicians better weigh the risks and benefits of more aggressive or more conservative anticancer therapies, especially for elderly patients.

Previous studies have suggested laterality to not be an independent predictor of OS in CSCLC patients $(6,7,10)$. 
In our study, although the detailed location of tumor was further refined based on lobes, the associations between prognosis and location of the tumor remained nonsignificant.

The current guidelines for managing SCLC do not classify the standard treatment of CSCLC in detail $(5,17)$. Surgical resection plays a significant role in the treatment of NSCLC patients (18), while its indications and precise roles in SCLC patients remains controversial. Although a Cochrane review of randomized controlled trials (RCTs) in 2017 did not provide support for surgical intervention in limited-stage SCLC, the conclusions were inherently limited in view of very low-certainty evidence and the absence of contemporary data (19). Recently, a growing number of studies have indicated that surgery can improve the OS of patients with limited stage SCLC (20-22). In addition, compared to patients with pure SCLC, CSCLC patients tended to more frequently undergo surgery ( $45 \%$ vs. $3 \% ; \mathrm{P}<0.001)(11)$. The latest ESMO Clinical Practice Guidelines states that in the context of a multimodal treatment approach, surgery may be considered in patients suspected of CSCLC (5). In our study, the multivariate Cox analyses showed that CSCLC patients receiving surgery had better prognosis (HR 0.46, 95\% CI: $0.36-0.58, \mathrm{P}<0.001$ ). For chemotherapy, CSCLC patients had relatively lower sensitivity to chemotherapies than SCLC patients due to the presence of NSCLC histology (10). The role of adjuvant radiotherapy has been demonstrated in stage IIA-IIIA CSCLC patients, with the median OS being 9 and 21 months, respectively, in patients who underwent surgery alone versus those who also underwent adjuvant radiotherapy $(\mathrm{P}=0.03)$ (7). However, the effect of radiation therapy on CSCLC patients remains unknown (4). In the recent years, new treatment strategies, including targeted therapies, checkpoint blockade immunotherapies, and combined treatments have largely improved the outcome of both SCLC and NSCLC $(23,24)$. Gene mutation and transcriptional regulators in CSCLC has been gained in recent years $(8,25-27)$. It remains to be evaluated if CSCLC compared with SCLC may still present a better response to these treatments in term of clinical benefit and survival.

Several limitations of our study should be noted. First, as a retrospective study with the risk of potential selection bias, our findings need to be confirmed in prospective multicenter clinical trials. Second, CSCLC is a heterogeneous cancer, and thus the type of NSCLC component and genetic mutations might affect prognosis and response to treatment. However, no detailed information on these issues is available in SEER database and were thus not examined. Moreover, the data on targeted therapies and immunotherapies were lacking due to the constraints of the SEER database.

\section{Conclusions}

In summary, we found that the prognosis of CSCLC patients was significantly worse than that of NSCLC patients, but comparable to that of pure SCLC patients. Additionally, we developed and validated a prognostic nomogram for predicting the 6-month, 1-year, and 3-year OS in CSCLC patients with good discrimination and calibration, which has not been undertaken in previous studies. The online calculator for our nomogram provided opportunities for fast individualized risk stratification and prognosis prediction in clinic.

\section{Acknowledgments}

The authors appreciate the academic support from the AME Lung Cancer Collaborative Group and the efforts of the SEER program in establishing the SEER database.

Funding: This work was supported by National Nature Science Foundation of China (grant No. 91859203 and 81871890), the Sichuan Science and Technology Program (grant No. 2020YFS0572), and Sichuan Science and Technology Program (No. 2019YFS0339). The funders had no role in study design, data collection and analysis, decision to publish, or preparation of the manuscript.

\section{Footnote}

Reporting Checklist: The authors have completed the TRIPOD reporting checklist. Available at https://dx.doi. org/10.21037/tlcr-21-804

Conflicts of Interest: All authors have completed the ICMJE uniform disclosure form (available at https://dx.doi. org/10.21037/tlcr-21-804). The authors have no conflicts of interest to declare.

Ethical Statement: The authors are accountable for all aspects of the work in ensuring that questions related to the accuracy or integrity of any part of the work are appropriately investigated and resolved. The study was conducted according to the criteria set by the declaration of Helsinki (as revised in 2013). 
Open Access Statement: This is an Open Access article distributed in accordance with the Creative Commons Attribution-NonCommercial-NoDerivs 4.0 International License (CC BY-NC-ND 4.0), which permits the noncommercial replication and distribution of the article with the strict proviso that no changes or edits are made and the original work is properly cited (including links to both the formal publication through the relevant DOI and the license). See: https://creativecommons.org/licenses/by-nc-nd/4.0/.

\section{References}

1. Rudin CM, Brambilla E, Faivre-Finn C, et al. Small-cell lung cancer. Nat Rev Dis Primers 2021;7:3.

2. Thai AA, Solomon BJ, Sequist LV, et al. Lung cancer. Lancet 2021;398:535-54.

3. Travis WD, Brambilla E, Nicholson AG, et al. The 2015 World Health Organization Classification of Lung Tumors: Impact of Genetic, Clinical and Radiologic Advances Since the 2004 Classification. J Thorac Oncol 2015;10:1243-60.

4. Qin J, Lu H. Combined small-cell lung carcinoma. Onco Targets Ther 2018;11:3505-11.

5. Dingemans AC, Früh M, Ardizzoni A, et al. Smallcell lung cancer: ESMO Clinical Practice Guidelines for diagnosis, treatment and follow-up 2 . Ann Oncol 2021;32:839-53

6. Xie T, Li Y, Ying J, et al. Whole exome sequencing (WES) analysis of transformed small cell lung cancer (SCLC) from lung adenocarcinoma (LUAD). Transl Lung Cancer Res 2020;9:2428-39.

7. He J, Xu S, Pan H, et al. Treatments for combined small cell lung cancer patients. Transl Lung Cancer Res 2020;9:1785-94.

8. Zhang J, Zhang L, Luo J, et al. Comprehensive genomic profiling of combined small cell lung cancer. Transl Lung Cancer Res 2021;10:636-50.

9. Zhao X, McCutcheon JN, Kallakury B, et al. Combined Small Cell Carcinoma of the Lung: Is It a Single Entity? J Thorac Oncol 2018;13:237-45.

10. Men Y, Hui Z, Liang J, et al. Further understanding of an uncommon disease of combined small cell lung cancer: clinical features and prognostic factors of 114 cases. Chin J Cancer Res 2016;28:486-94.

11. Babakoohi S, Fu P, Yang M, et al. Combined SCLC clinical and pathologic characteristics. Clin Lung Cancer 2013;14:113-9.

12. Balachandran VP, Gonen M, Smith JJ, et al. Nomograms in oncology: more than meets the eye. Lancet Oncol 2015;16:e173-80.

13. Vickers AJ, Elkin EB. Decision curve analysis: a novel method for evaluating prediction models. Med Decis Making 2006;26:565-74.

14. Davis S, Stanley KE, Yesner R, et al. Small-cell carcinoma of the lung--survival according to histologic subtype: a Veterans Administration Lung Group Study. Cancer 1981;47:1863-6.

15. Li D, Xu X, Liu J, et al. Small cell lung cancer (SCLC) incidence and trends vary by gender, geography, age, and subcategory based on population and hospital cancer registries in Hebei, China (2008-2017). Thorac Cancer 2020;11:2087-93.

16. Abdel-Rahman O. Changing epidemiology of elderly small cell lung cancer patients over the last 40 years; a SEER database analysis. Clin Respir J 2018;12:1093-9.

17. Kalemkerian GP, Loo BW, Akerley W, et al. NCCN Guidelines Insights: Small Cell Lung Cancer, Version 2.2018. J Natl Compr Canc Netw 2018;16:1171-82.

18. Ettinger DS, Wood DE, Aisner DL, et al. NCCN Guidelines Insights: Non-Small Cell Lung Cancer, Version 2.2021. J Natl Compr Canc Netw 2021;19:254-66.

19. Barnes H, See K, Barnett S, et al. Surgery for limitedstage small-cell lung cancer. Cochrane Database Syst Rev 2017;4:CD011917.

20. Wang Y, Zheng Q, Jia B, et al. Effects of Surgery on Survival of Early-Stage Patients With SCLC: Propensity Score Analysis and Nomogram Construction in SEER Database. Front Oncol 2020;10:626.

21. Uprety D, Arjyal L, Vallatharasu Y, et al. Utilization of Surgery and Its Impact on Survival in Patients With Early Stage Small-cell Lung Cancer in the United States. Clin Lung Cancer 2020;21:186-193.e2.

22. Yang CJ, Chan DY, Shah SA, et al. Long-term Survival After Surgery Compared With Concurrent Chemoradiation for Node-negative Small Cell Lung Cancer. Ann Surg 2018;268:1105-12.

23. Pathak R, De Lima Lopes G, Yu H, et al. Comparative efficacy of chemoimmunotherapy versus immunotherapy for advanced non-small cell lung cancer: A network metaanalysis of randomized trials. Cancer 2021;127:709-19.

24. Serzan MT, Farid S, Liu SV. Drugs in development for small cell lung cancer. J Thorac Dis 2020;12:6298-307.

25. Baine MK, Hsieh MS, Lai WV, et al. SCLC Subtypes Defined by ASCL1, NEUROD1, POU2F3, and YAP1: A Comprehensive Immunohistochemical and Histopathologic Characterization. J Thorac Oncol 
2020;15:1823-35.

26. Shibata M, Ham K, Hoque MO. A time for YAP1:

Tumorigenesis, immunosuppression and targeted therapy. Int J Cancer 2018;143:2133-44.

27. Lee BS, Park DI, Lee DH, et al. Hippo effector YAP

Cite this article as: Yang L, Zhou Y, Wang G, Liu D, Chen B, Pu D, Correale P, Rades D, Tomita Y, Inno A, Santarpia M, Li Y, Li W. Clinical features and prognostic factors of combined small cell lung cancer: development and validation of a nomogram based on the SEER database. Transl Lung Cancer Res 2021;10(11):4250-4265. doi: 10.21037/tlcr-21-804 directly regulates the expression of $\mathrm{PD}-\mathrm{L} 1$ transcripts in EGFR-TKI-resistant lung adenocarcinoma. Biochem Biophys Res Commun 2017;491:493-9.

(English Language Editor: J. Gray) 
Supplementary

Table S1 Demographics and clinicopathological characteristics of all patients after PSM

\begin{tabular}{|c|c|c|c|c|c|c|c|c|c|c|}
\hline \multirow{2}{*}{ Characteristics } & \multicolumn{2}{|c|}{$\operatorname{CSCLC}(n=871)$} & \multicolumn{2}{|c|}{ NSCLC (n=3,484) } & \multirow{2}{*}{$\mathrm{P}_{1}$ value } & \multicolumn{2}{|c|}{$\operatorname{CSCLC~}(\mathrm{n}=871)$} & \multicolumn{2}{|c|}{ Pure SCLC $(n=3,366)$} & \multirow{2}{*}{$P_{2}$ value } \\
\hline & Number & $\%$ & Number & $\%$ & & Number & $\%$ & Number & $\%$ & \\
\hline Age (years) & & & & & 0.793 & & & & & 0.935 \\
\hline$\leq 60$ & 229 & 26.3 & 956 & 27.4 & & 229 & 26.3 & 903 & 26.8 & \\
\hline $60-70$ & 305 & 35.0 & 1,201 & 34.5 & & 305 & 35.0 & 1,180 & 35.1 & \\
\hline$>70$ & 337 & 38.7 & 1,327 & 38.1 & & 337 & 38.7 & 1,283 & 38.1 & \\
\hline Gender & & & & & 0.830 & & & & & 0.965 \\
\hline Female & 378 & 43.4 & 1,498 & 43.0 & & 378 & 43.4 & 1,458 & 43.3 & \\
\hline Male & 493 & 56.6 & 1,986 & 57.0 & & 493 & 56.6 & 1,908 & 56.7 & \\
\hline Race & & & & & 0.974 & & & & & 0.970 \\
\hline White & 727 & 83.5 & 2,904 & 83.4 & & 727 & 83.5 & 2,818 & 83.7 & \\
\hline Black & 109 & 12.5 & 434 & 12.5 & & 109 & 12.5 & 411 & 12.2 & \\
\hline Other & 35 & 4.0 & 146 & 4.2 & & 35 & 4.0 & 137 & 4.1 & \\
\hline Site & & & & & 0.970 & & & & & 0.973 \\
\hline Left upper lobe & 217 & 24.9 & 832 & 23.9 & & 217 & 24.9 & 830 & 24.7 & \\
\hline Left lower lobe & 100 & 11.5 & 427 & 12.3 & & 100 & 11.5 & 390 & 11.6 & \\
\hline Right upper lobe & 270 & 31.0 & 1,092 & 31.3 & & 270 & 31.0 & 1,011 & 30.0 & \\
\hline Right middle lobe & 32 & 3.7 & 145 & 4.2 & & 32 & 3.7 & 133 & 4.0 & \\
\hline Right lower lobe & 100 & 11.5 & 379 & 10.9 & & 100 & 11.5 & 388 & 11.5 & \\
\hline Main bronchus & 66 & 7.6 & 261 & 7.5 & & 66 & 7.6 & 244 & 7.2 & \\
\hline Unspecific & 86 & 9.9 & 348 & 10.0 & & 86 & 9.9 & 370 & 11.0 & \\
\hline $\mathrm{T}$ & & & & & 0.994 & & & & & 0.870 \\
\hline $\mathrm{T} 1$ & 184 & 21.1 & 740 & 21.2 & & 184 & 21.1 & 690 & 20.5 & \\
\hline $\mathrm{T} 2$ & 291 & 33.4 & 1,168 & 33.5 & & 291 & 33.4 & 1,097 & 32.6 & \\
\hline T3 & 36 & 4.1 & 150 & 4.3 & & 36 & 4.1 & 153 & 4.5 & \\
\hline $\mathrm{T} 4$ & 360 & 41.3 & 1,426 & 40.9 & & 360 & 41.3 & 1,426 & 42.4 & \\
\hline $\mathrm{N}$ & & & & & 0.867 & & & & & 0.457 \\
\hline NO & 285 & 32.7 & 1,115 & 32.0 & & 285 & 32.7 & 1,025 & 30.5 & \\
\hline $\mathrm{N} 1$ & 83 & 9.5 & 358 & 10.3 & & 83 & 9.5 & 302 & 9.0 & \\
\hline N2 & 375 & 43.1 & 1,520 & 43.6 & & 375 & 43.1 & 1,544 & 45.9 & \\
\hline N3 & 128 & 14.7 & 491 & 14.1 & & 128 & 14.7 & 495 & 14.7 & \\
\hline M & & & & & 0.220 & & & & & 0.243 \\
\hline MO & 460 & 52.8 & 1,759 & 50.5 & & 460 & 52.8 & 1,703 & 50.6 & \\
\hline M1 & 411 & 47.2 & 1,725 & 49.5 & & 411 & 47.2 & 1,663 & 49.4 & \\
\hline Surgery & & & & & 0.384 & & & & & 0.141 \\
\hline None & 626 & 71.9 & 2,555 & 73.3 & & 626 & 71.9 & 2,502 & 74.3 & \\
\hline Yes & 245 & 28.1 & 929 & 26.7 & & 245 & 28.1 & 864 & 25.7 & \\
\hline Radiation & & & & & 0.457 & & & & & 0.791 \\
\hline None & 473 & 54.3 & 1,843 & 52.9 & & 473 & 54.3 & 1,811 & 53.8 & \\
\hline Yes & 398 & 45.7 & 1,641 & 47.1 & & 398 & 45.7 & 1,555 & 46.2 & \\
\hline Chemotherapy & & & & & 0.775 & & & & & 0.325 \\
\hline None & 306 & 35.1 & 1,206 & 34.6 & & 306 & 35.1 & 1,123 & 33.4 & \\
\hline Yes & 565 & 64.9 & 2,278 & 65.4 & & 565 & 64.9 & 2,243 & 66.6 & \\
\hline
\end{tabular}

PSM, propensity score matching; CSCLC, combined small cell lung cancer; NSCLC, non-small cell lung cancer; SCLC, small cell lung cancer. 
Table S2 Univariate and multivariate Cox analyses of LCSS for NSCLC and CSCLC patients in unmatched and matched cohorts

\begin{tabular}{|c|c|c|c|c|c|c|c|c|c|c|c|c|}
\hline \multirow{3}{*}{ Characteristics } & \multicolumn{6}{|c|}{$\operatorname{CSCLC}(n=871)$ and NSCLC $(n=280,391)$} & \multicolumn{6}{|c|}{$1: 4$ match of CSCLC $(n=871)$ and NSCLC $(n=3,484)$} \\
\hline & \multicolumn{3}{|c|}{ Univariable } & \multicolumn{3}{|c|}{ Multivariable } & \multicolumn{3}{|c|}{ Univariable } & \multicolumn{3}{|c|}{ Multivariable } \\
\hline & $\mathrm{HR}$ & $95 \% \mathrm{Cl}$ & $\mathrm{P}$ & HR & $95 \% \mathrm{Cl}$ & $\mathrm{P}$ & $\mathrm{HR}$ & $95 \% \mathrm{Cl}$ & $\mathrm{P}$ & $\mathrm{HR}$ & $95 \% \mathrm{Cl}$ & $\mathrm{P}$ \\
\hline \multicolumn{13}{|l|}{ Age (years) } \\
\hline$\leq 60$ & 1 & & & 1 & & & 1 & & & 1 & & \\
\hline $60-70$ & 0.97 & $0.96-0.98$ & $<0.001$ & 1.07 & $1.06-1.08$ & $<0.001$ & 1.10 & $1.01-1.21$ & 0.031 & 1.14 & $1.04-1.25$ & 0.005 \\
\hline$>70$ & 1.15 & $1.14-1.17$ & $<0.001$ & 1.20 & $1.19-1.22$ & $<0.001$ & 1.23 & $1.13-1.35$ & $<0.001$ & 1.24 & $1.13-1.36$ & $<0.001$ \\
\hline \multicolumn{13}{|l|}{ Gender } \\
\hline Female & 1 & & & 1 & & & 1 & & & 1 & & \\
\hline Male & 1.27 & $1.26-1.28$ & $<0.001$ & 1.21 & $1.20-1.22$ & $<0.001$ & 1.30 & $1.21-1.39$ & $<0.001$ & 1.28 & $1.19-1.37$ & $<0.001$ \\
\hline \multicolumn{13}{|l|}{ Race } \\
\hline White & 1 & & & 1 & & & 1 & & & 1 & & \\
\hline Black & 1.14 & $1.12-1.15$ & $<0.001$ & 0.98 & $0.96-0.99$ & 0.001 & 1.16 & $1.05-1.29$ & 0.005 & 0.97 & $0.88-1.08$ & 0.626 \\
\hline Other & 0.90 & $0.89-0.92$ & $<0.001$ & 0.75 & $0.73-0.76$ & $<0.001$ & 0.92 & $0.77-1.10$ & 0.363 & 0.66 & $0.55-0.80$ & $<0.001$ \\
\hline \multicolumn{13}{|l|}{ Primary site } \\
\hline Left upper lobe & 1 & & & 1 & & & 1 & & & 1 & & \\
\hline Left lower lobe & 1.00 & $0.98-1.01$ & 0.597 & 1.04 & $1.02-1.06$ & $<0.001$ & 1.03 & $0.91-1.16$ & 0.683 & 1.04 & $0.91-1.17$ & 0.586 \\
\hline Right upper lobe & 1.00 & $0.99-1.01$ & 0.647 & 0.98 & $0.97-1.00$ & 0.013 & 1.01 & $0.92-1.11$ & 0.882 & 0.92 & $0.84-1.01$ & 0.092 \\
\hline Right middle lobe & 0.97 & $0.94-0.99$ & 0.005 & 0.99 & $0.97-1.02$ & 0.437 & 1.19 & $0.99-1.43$ & 0.060 & 1.19 & $0.99-1.43$ & 0.061 \\
\hline Right lower lobe & 1.04 & $1.03-1.06$ & $<0.001$ & 1.06 & $1.04-1.08$ & $<0.001$ & 1.09 & $0.96-1.24$ & 0.186 & 1.09 & $0.95-1.24$ & 0.211 \\
\hline Main bronchus & 1.87 & $1.83-1.91$ & $<0.001$ & 1.22 & $1.19-1.25$ & $<0.001$ & 1.68 & $1.46-1.93$ & $<0.001$ & 1.21 & $1.05-1.39$ & 0.009 \\
\hline Unspecific & 1.99 & $1.96-2.02$ & $<0.001$ & 1.21 & $1.19-1.23$ & $<0.001$ & 1.88 & $1.66-2.14$ & $<0.001$ & 1.23 & $1.08-1.40$ & 0.002 \\
\hline \multicolumn{13}{|l|}{$\mathrm{T}$} \\
\hline $\mathrm{T} 1$ & 1 & & & 1 & & & 1 & & & 1 & & \\
\hline $\mathrm{T} 2$ & 1.92 & $1.90-1.95$ & $<0.001$ & 1.60 & $1.57-1.62$ & $<0.001$ & 1.70 & $1.52-1.89$ & $<0.001$ & 1.59 & $1.42-1.78$ & $<0.001$ \\
\hline T3 & 2.81 & $2.75-2.86$ & $<0.001$ & 2.08 & $2.03-2.12$ & $<0.001$ & 2.34 & $1.95-2.81$ & $<0.001$ & 1.90 & $1.57-2.29$ & $<0.001$ \\
\hline T4 & 4.06 & $4.01-4.12$ & $<0.001$ & 2.09 & $2.05-1.12$ & $<0.001$ & 3.02 & $2,73-3.35$ & $<0.001$ & 1.93 & $1.73-2.16$ & $<0.001$ \\
\hline \multicolumn{13}{|l|}{$\mathrm{N}$} \\
\hline No & 1 & & & 1 & & & 1 & & & 1 & & \\
\hline $\mathrm{N} 1$ & 1.62 & $1.60-1.65$ & $<0.001$ & 1.49 & $1.47-1.52$ & $<0.001$ & 1.34 & $1.17-1.53$ & $<0.001$ & 1.38 & $1.20-1.58$ & $<0.001$ \\
\hline N2 & 2.70 & $2.67-2.73$ & $<0.001$ & 1.63 & $1.61-1.65$ & $<0.001$ & 2.46 & $2.52-2.68$ & $<0.001$ & 1.72 & $1.56-1.90$ & $<0.001$ \\
\hline N3 & 3.14 & $3.09-3.18$ & $<0.001$ & 1.63 & $1.60-1.65$ & $<0.001$ & 2.80 & $2.50-3.12$ & $<0.001$ & 1.61 & $1.42-1.82$ & $<0.001$ \\
\hline \multicolumn{13}{|l|}{ M } \\
\hline MO & 1 & & & 1 & & & 1 & & & 1 & & \\
\hline M1 & 3.37 & $3.34-3.40$ & $<0.001$ & 1.92 & $1.90-1.94$ & $<0.001$ & 3.10 & $2.88-3.34$ & $<0.001$ & 2 & $1.84-2.17$ & $<0.001$ \\
\hline \multicolumn{13}{|l|}{ Histology } \\
\hline CSCLC & 1 & & & 1 & & & 1 & & & 1 & & \\
\hline NSCLC & 0.77 & $0.72-0.83$ & $<0.001$ & 0.74 & $0.69-0.80$ & $<0.001$ & 0.80 & $0.73-0.87$ & $<0.001$ & 0.73 & $0.67-0.79$ & $<0.001$ \\
\hline \multicolumn{13}{|l|}{ Surgery } \\
\hline None & 1 & & & 1 & & & 1 & & & 1 & & \\
\hline Yes & 0.18 & $0.18-0.19$ & 0.280 & 0.27 & $0.27-0.28$ & $<0.001$ & 0.23 & $0.21-0.26$ & $<0.001$ & 0.35 & $0.31-0.39$ & $<0.001$ \\
\hline \multicolumn{13}{|l|}{ Radiation } \\
\hline None & 1 & & & 1 & & & 1 & & & 1 & & \\
\hline Yes & 1.39 & $1.38-1.40$ & $<0.001$ & 0.91 & $0.90-0.92$ & $<0.001$ & 1.24 & $1.16-1.33$ & $<0.001$ & 0.93 & $0.86-1.00$ & 0.050 \\
\hline \multicolumn{13}{|l|}{ Chemotherapy } \\
\hline None & 1 & & & 1 & & & 1 & & & 1 & & \\
\hline Yes & 1.12 & $1.11-1.13$ & $<0.001$ & 0.52 & $0.52-0.53$ & $<0.001$ & 1.06 & $0.98-1.14$ & 0.151 & 0.49 & $0.45-0.54$ & $<0.001$ \\
\hline
\end{tabular}

LCSS, lung cancer-specific survival; CSCLC, combined small cell lung cancer; NSCLC, non-small cell lung cancer; HR, hazard ratio; Cl, confidence interval. 
Table S3 Univariate and multivariate Cox analyses of LCSS for NSCLC and pure SCLC patients in unmatched and matched cohorts

\begin{tabular}{|c|c|c|c|c|c|c|c|c|c|c|c|c|}
\hline \multirow{3}{*}{ Characteristics } & \multicolumn{6}{|c|}{$\operatorname{CSCLC}(n=871)$ and pure SCLC $(n=45,433)$} & \multicolumn{6}{|c|}{$1: 4$ match of CSCLC $(n=793)$ and pure SCLC $(n=3,366)$} \\
\hline & \multicolumn{3}{|c|}{ Univariable } & \multicolumn{3}{|c|}{ Multivariable } & \multicolumn{3}{|c|}{ Univariable } & \multicolumn{3}{|c|}{ Multivariable } \\
\hline & $\mathrm{HR}$ & $95 \% \mathrm{Cl}$ & $\mathrm{P}$ & HR & $95 \% \mathrm{Cl}$ & $\mathrm{P}$ & HR & $95 \% \mathrm{Cl}$ & $\mathrm{P}$ & HR & $95 \% \mathrm{Cl}$ & $P$ \\
\hline \multicolumn{13}{|l|}{ Age (years) } \\
\hline$\leq 60$ & 1 & & & 1 & & & 1 & & & 1 & & \\
\hline $60-70$ & 1.14 & $1.12-1.17$ & $<0.001$ & 1.12 & $1.09-1.44$ & $<0.001$ & 1.12 & $1.03-1.23$ & 0.011 & 1.14 & $1.04-1.24$ & 0.005 \\
\hline$>70$ & 1.53 & $1.49-1.57$ & $<0.001$ & 1.36 & $1.32-1.39$ & $<0.001$ & 1.47 & $1.35-1.60$ & $<0.001$ & 1.43 & $1.31-1.56$ & $<0.001$ \\
\hline \multicolumn{13}{|l|}{ Gender } \\
\hline Female & 1 & & & 1 & & & 1 & & & 1 & & \\
\hline Male & 1.17 & $1.15-1.20$ & $<0.001$ & 1.15 & $1.13-1.17$ & $<0.001$ & 1.38 & $1.29-1.48$ & $<0.001$ & 1.29 & $1.21-1.39$ & $<0.001$ \\
\hline \multicolumn{13}{|l|}{ Race } \\
\hline White & 1 & & & 1 & & & 1 & & & & & \\
\hline Black & 0.92 & $0.89-0.95$ & $<0.001$ & 0.93 & $0.89-0.96$ & $<0.001$ & 1.11 & $1.00-1.23$ & 0.057 & & & \\
\hline Other & 0.92 & $0.87-0.97$ & 0.001 & 0.88 & $0.83-0.92$ & $<0.001$ & 1.00 & $0.84-1.19$ & 0.985 & & & \\
\hline \multicolumn{13}{|l|}{ Primary site } \\
\hline Left upper lobe & 1 & & & 1 & & & 1 & & & 1 & & \\
\hline Left lower lobe & 1.06 & $1.02-1.10$ & 0.006 & 1.03 & $0.99-1.07$ & 0.115 & 0.95 & $0.84-1.08$ & 0.452 & 1.04 & $0.92-1.17$ & 0.570 \\
\hline Right upper lobe & 0.99 & $0.96-1.02$ & 0.332 & 1.00 & $0.97-1.03$ & 0.992 & 0.94 & $0.86-1.04$ & 0.221 & 0.94 & $0.85-1.03$ & 0.182 \\
\hline Right middle lobe & 0.98 & $0.93-1.04$ & 0.560 & 0.99 & $0.94-1.04$ & 0.623 & 0.90 & $0.75-1.08$ & 0.255 & 0.84 & $0.70-1.02$ & 0.075 \\
\hline Right lower lobe & 1.07 & $1.04-1.11$ & $<0.001$ & 1.04 & $1.00-1.07$ & 0.067 & 0.98 & $0.86-1.10$ & 0.686 & 1.04 & $0.92-1.18$ & 0.516 \\
\hline Main bronchus & 1.13 & $1.10-1.18$ & $<0.001$ & 1.05 & $1.02-1.09$ & 0.005 & 1.35 & $1.17-1.55$ & $<0.001$ & 1.06 & $0.92-1.22$ & 0.443 \\
\hline Unspecific & 1.32 & $1.28-1.37$ & $<0.001$ & 1.07 & $1.04-1.11$ & 0.000 & 1.61 & $1.43-1.82$ & $<0.001$ & 1.07 & $0.95-1.21$ & 0.274 \\
\hline \multicolumn{13}{|l|}{$\mathrm{T}$} \\
\hline $\mathrm{T} 1$ & 1 & & & 1 & & & 1 & & & 1 & & \\
\hline $\mathrm{T} 2$ & 1.35 & $1.30-1.40$ & $<0.001$ & 1.26 & $1.21-1.31$ & $<0.001$ & 1.74 & $1.57-1.93$ & $<0.001$ & 1.33 & $1.20-1.48$ & $<0.001$ \\
\hline T3 & 1.53 & $1.45-1.62$ & $<0.001$ & 1.40 & $1.32-1.48$ & $<0.001$ & 2.35 & $1.97-2.81$ & $<0.001$ & 1.57 & $1.31-1.89$ & $<0.001$ \\
\hline T4 & 1.77 & $1.72-1.83$ & $<0.001$ & 1.47 & $1.42-1.52$ & $<0.001$ & 2.85 & $2.57-3.15$ & $<0.001$ & 1.66 & $1.48-1.85$ & $<0.001$ \\
\hline \multicolumn{13}{|l|}{$\mathrm{N}$} \\
\hline No & 1 & & & 1 & & & 1 & & & 1 & & \\
\hline $\mathrm{N} 1$ & 1.11 & $1.06-1.16$ & $<0.001$ & 1.14 & $1.09-1.19$ & $<0.001$ & 1.37 & $1.20-1.57$ & $<0.001$ & 1.40 & $1.22-1.60$ & $<0.001$ \\
\hline N2 & 1.44 & $1.40-1.48$ & $<0.001$ & 1.34 & $1.30-1.38$ & $<0.001$ & 2.24 & $2.05-2.43$ & $<0.001$ & 1.57 & $1.43-1.73$ & $<0.001$ \\
\hline N3 & 1.52 & $1.47-1.58$ & $<0.001$ & 1.36 & $1.31-1.41$ & $<0.001$ & 2.36 & $2.11-2.63$ & $<0.001$ & 1.39 & $1.23-1.57$ & $<0.001$ \\
\hline \multicolumn{13}{|l|}{ M } \\
\hline Mo & 1 & & & 1 & & & 1 & & & 1 & & \\
\hline M1 & 2.25 & $2.21-2.30$ & $<0.001$ & 1.88 & $1.84-1.92$ & $<0.001$ & 3.18 & $2.96-3.42$ & $<0.001$ & 2.14 & $1.98-2.32$ & $<0.001$ \\
\hline \multicolumn{13}{|l|}{ Histology } \\
\hline CSCLC & 1 & & & 1 & & & 1 & & & & & \\
\hline Pure SCLC & 1.38 & $1.28-1.49$ & $<0.001$ & 1.06 & $0.98-1.15$ & 0.134 & 1.02 & $0.94-1.11$ & 0.669 & & & \\
\hline \multicolumn{13}{|l|}{ Surgery } \\
\hline None & 1 & & & 1 & & & 1 & & & 1 & & \\
\hline Yes & 0.36 & $0.33-0.38$ & $<0.001$ & 0.43 & $0.40-0.46$ & $<0.001$ & 0.33 & $0.30-0.36$ & $<0.001$ & 0.49 & $0.44-0.55$ & $<0.001$ \\
\hline \multicolumn{13}{|l|}{ Radiation } \\
\hline None & 1 & & & 1 & & & 1 & & & 1 & & \\
\hline Yes & 0.49 & $0.48-0.50$ & $<0.001$ & 0.68 & $0.40-0.46$ & $<0.001$ & 0.73 & $0.68-0.78$ & $<0.001$ & 0.77 & $0.72-0.83$ & $<0.001$ \\
\hline \multicolumn{13}{|l|}{ Chemotherapy } \\
\hline None & 1 & & & 1 & & & 1 & & & 1 & & \\
\hline Yes & 0.37 & $0.36-0.37$ & $<0.001$ & 0.39 & $0.38-0.39$ & $<0.001$ & 0.59 & $0.55-0.64$ & $<0.001$ & 0.51 & $0.47-0.56$ & $<0.001$ \\
\hline
\end{tabular}

LCSS, lung cancer-specific survival; CSCLC, combined small cell lung cancer; SCLC, small cell lung cancer; HR, hazard ratio; Cl, confidence interval. 
Table S4 Demographics and clinicopathologic characteristics of the training and validation data sets

\begin{tabular}{|c|c|c|c|c|c|c|c|}
\hline \multirow{2}{*}{ Characteristics } & \multicolumn{2}{|c|}{ All patients $(n=871)$} & \multicolumn{2}{|c|}{ Training data set $(\mathrm{N}=602)$} & \multicolumn{2}{|c|}{ Validation data set $(\mathrm{N}=269)$} & \multirow{2}{*}{$P$ value } \\
\hline & Number & $\%$ & Number & $\%$ & Number & $\%$ & \\
\hline Age (years) & & & & & & & 0.009 \\
\hline$\leq 60$ & 229 & 26.3 & 174 & 28.9 & 55 & 20.4 & \\
\hline $60-70$ & 305 & 35.0 & 194 & 32.2 & 111 & 41.3 & \\
\hline$>70$ & 337 & 38.7 & 234 & 38.9 & 103 & 38.3 & \\
\hline Gender & & & & & & & 0.396 \\
\hline Female & 378 & 43.4 & 267 & 44.4 & 111 & 41.3 & \\
\hline Male & 493 & 56.6 & 335 & 55.6 & 158 & 58.7 & \\
\hline Race & & & & & & & 0.269 \\
\hline White & 727 & 83.5 & 508 & 84.4 & 219 & 81.4 & \\
\hline Black & 109 & 12.5 & 74 & 12.3 & 35 & 13.0 & \\
\hline Other & 35 & 4.0 & 20 & 3.3 & 15 & 5.6 & \\
\hline Site & & & & & & & 0.902 \\
\hline Left upper lobe & 217 & 24.9 & 154 & 25.6 & 63 & 23.4 & \\
\hline Left lower lobe & 100 & 11.5 & 70 & 11.6 & 30 & 11.2 & \\
\hline Right upper lobe & 270 & 31.0 & 184 & 30.6 & 86 & 32.0 & \\
\hline Right middle lobe & 32 & 3.7 & 22 & 3.7 & 10 & 3.7 & \\
\hline Right lower lobe & 100 & 11.5 & 70 & 11.6 & 30 & 11.2 & \\
\hline Main bronchus & 66 & 7.6 & 41 & 6.8 & 25 & 9.3 & \\
\hline Unspecific & 86 & 9.9 & 61 & 10.1 & 25 & 9.3 & \\
\hline $\mathrm{T}$ & & & & & & & 0.032 \\
\hline T1 & 184 & 21.1 & 125 & 20.8 & 59 & 21.9 & \\
\hline T2 & 291 & 33.4 & 197 & 32.7 & 94 & 34.9 & \\
\hline T3 & 36 & 4.1 & 18 & 3.0 & 18 & 6.7 & \\
\hline T4 & 360 & 41.3 & 262 & 43.5 & 98 & 36.4 & \\
\hline N & & & & & & & 0.614 \\
\hline No & 285 & 32.7 & 194 & 32.2 & 91 & 33.8 & \\
\hline N1 & 83 & 9.5 & 61 & 10.1 & 22 & 8.2 & \\
\hline N2 & 375 & 43.1 & 263 & 43.7 & 112 & 41.6 & \\
\hline N3 & 128 & 14.7 & 84 & 14.0 & 44 & 16.4 & \\
\hline M & & & & & & & 0.891 \\
\hline MO & 460 & 52.8 & 317 & 52.7 & 143 & 53.2 & \\
\hline M1 & 411 & 47.2 & 285 & 47.3 & 126 & 46.8 & \\
\hline Surgery & & & & & & & 0.447 \\
\hline None & 626 & 71.9 & 428 & 71.1 & 198 & 73.6 & \\
\hline Yes & 245 & 28.1 & 174 & 28.9 & 71 & 26.4 & \\
\hline Radiation & & & & & & & 0.564 \\
\hline None & 473 & 54.3 & 323 & 53.7 & 150 & 55.8 & \\
\hline Yes & 398 & 45.7 & 279 & 46.3 & 119 & 44.2 & \\
\hline Chemotherapy & & & & & & & 0.077 \\
\hline None & 306 & 35.1 & 200 & 33.2 & 106 & 39.4 & \\
\hline Yes & 565 & 64.9 & 402 & 66.8 & 163 & 60.6 & \\
\hline
\end{tabular}



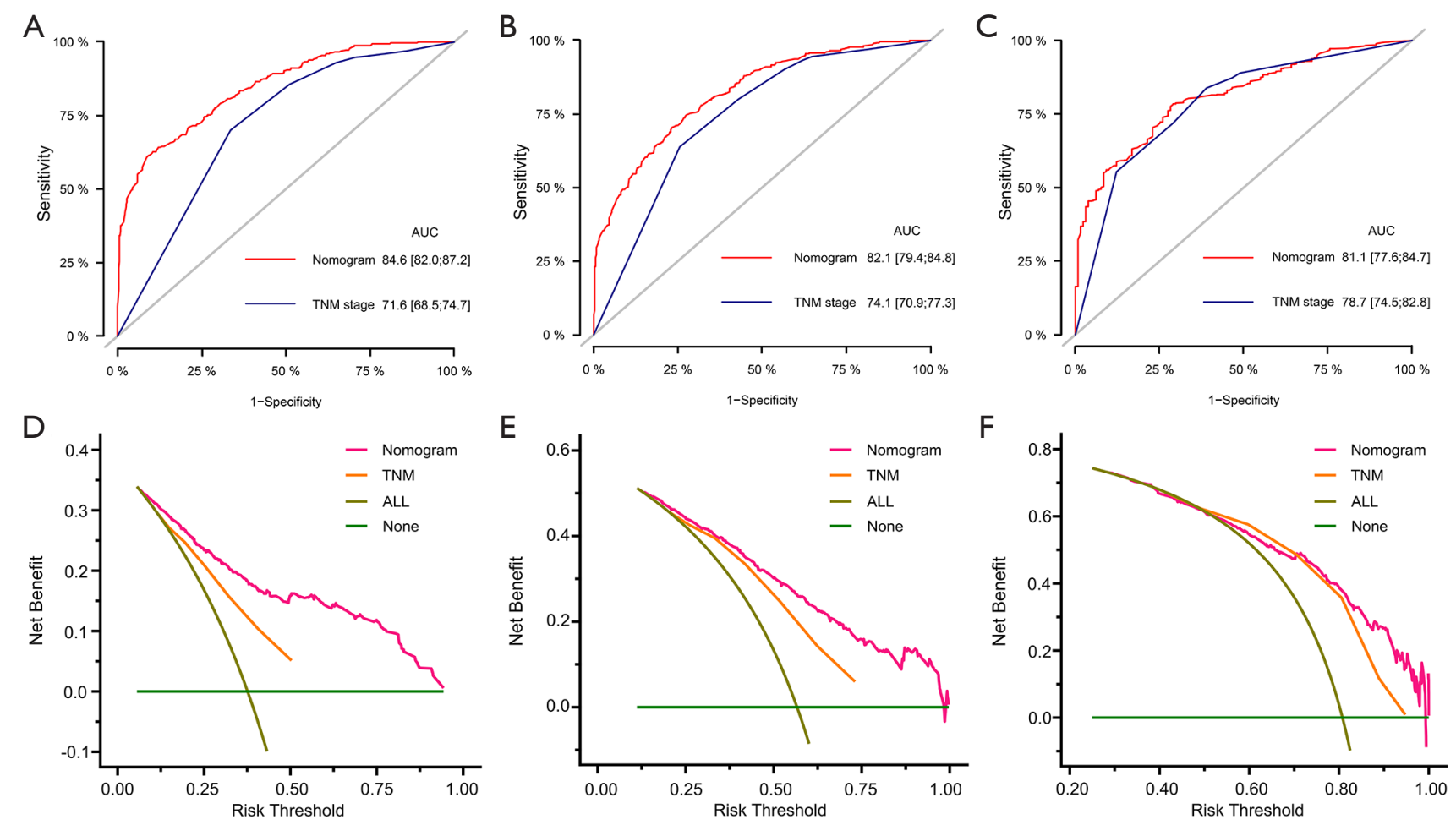

Figure S1 The receiver operating characteristic curves for predicting OS at (A) 6 months, (B) 1 year, and (C) 3 years of the nomogram and the TNM staging system. DCA analyses comparing the clinical utility of nomogram and TNM staging system at (D) 6 months, (E) 1 year, and (F) 3 years. OS, overall survival; DCA, decision curve analysis; AUC, area under the receiver operating characteristic curve.
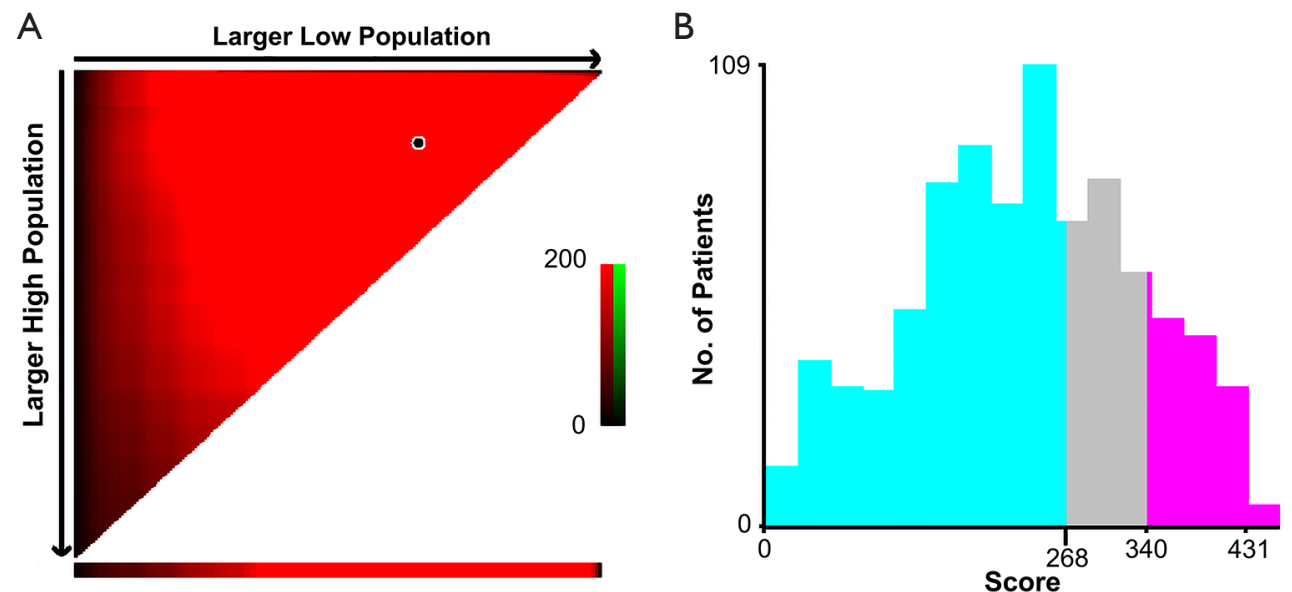

Figure S2 X-tile plots for identifying the optimal risk score cutoff values based on OS in CSCLC patients. (A) The optimum cutoff point is highlighted by the black dot. (B) Distributions of number of the CSCLC patients by risk scores, according to the nomogram. OS, overall survival; CSCLC, combined small cell lung cancer.

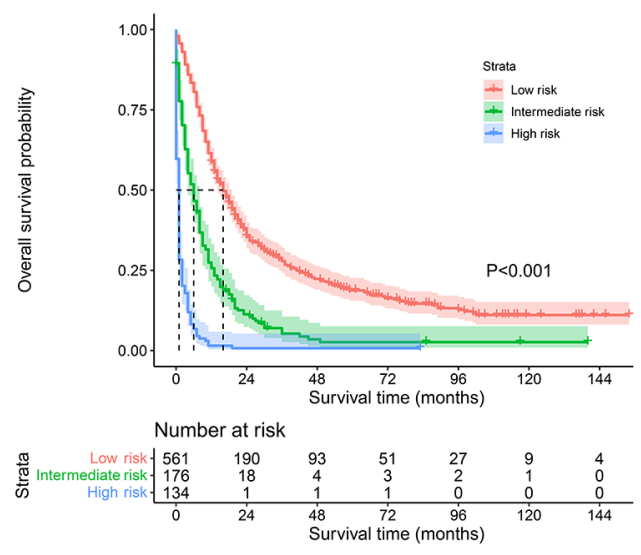

Figure S3 Kaplan-Meier curve of the low-, intermediate- and high-risk groups in CSCLC patients according to the risk scores. CSCLC, combined small cell lung cancer. 